Research Article

\title{
Water Production Problem in Gas Reservoirs: Concepts, Challenges, and Practical Solutions
}

\author{
Ali Akbar Roozshenas $\left(\mathbb{D},{ }^{1}\right.$ Hamed Hematpur $\mathbb{D}^{2},{ }^{2}$ Reza Abdollahi $\mathbb{D}^{2}{ }^{2}$ \\ and Hamid Esfandyari ${ }^{3}{ }^{3}$ \\ ${ }^{1}$ Department of Petroleum Engineering, Petroleum University of Technology, Ahwaz, Iran \\ ${ }^{2}$ EOR Research Department, Research Institute of Petroleum Industry, Tehran, Iran \\ ${ }^{3}$ Abadan Faculty of Petroleum Engineering, Petroleum University of Technology, Abadan, Iran \\ Correspondence should be addressed to Hamid Esfandyari; esfandyari_shirazu@yahoo.com
}

Received 2 June 2021; Revised 27 June 2021; Accepted 15 July 2021; Published 27 July 2021

Academic Editor: Samuel Yousefi

Copyright (C) 2021 Ali Akbar Roozshenas et al. This is an open access article distributed under the Creative Commons Attribution License, which permits unrestricted use, distribution, and reproduction in any medium, provided the original work is properly cited.

\begin{abstract}
Gas resources play a key role in nowadays energy supply and provide $24 \%$ of the diverse energy portfolio. Water encroachment is one of the main trapping mechanisms in gas reservoirs. It decreases recovery by reduction of reservoir life, limits productivity and efficiency of wells, and elevates safety risks in gas production. The lack of a comprehensive study about water production problems is the primary motivation for this study. Contrary to the serious concern over the standalone investigation of an actual water production case study, less concern is put to deal with the problem comprehensively through an investigation of all potential sources and mechanisms, required methods, and available techniques. This study presents the potential sources of the problem, methods to identify it, and approaches to address it. Firstly, possible sources are described. Secondly, the diagnostic techniques are expressed. Then, practical solutions used in actual cases to overcome problems are elaborated. The solutions include both welland reservoir-oriented approaches. Finally, all proper strategies are summarized to tackle the water problems in gas fields. The current study comprehensively presents the available methods for water control problems in parallel with conceptual and qualitative comparison. The finding of this study can be very constructive for better understanding of water sources, available diagnostic tools, and solutions for controlling water production in gas reservoirs and, consequently, taking the best decision in real case studies before attempting many water shut-off approaches.
\end{abstract}

\section{Introduction}

The decreasing trend of fossil resources discovery in parallel with the expanding demand for energy raises the eminence of techniques and approaches (reservoir-based and wellbased) applied to improve the recovery of current resources [1-12]. Many reservoirs are limited with water sources contained in water-bearing rocks called aquifers. Water production in gas reservoirs is more critical than in oil reservoirs. They are divided into two general categories based on aquifer support: volumetric reservoir and waterdrive reservoirs. Experiences have indicated that the recovery factor of volumetric reservoirs ranges between 80 and
90 percent due to remarkable pressure drop in the life of reservoirs, while it is significantly lower for the case of waterdrive gas reservoirs [13].

More than half of gas reservoirs in the world are associated with aquifers [14]. In cases that the water sources are large with high permeability of the water-bearing formation, water encroaches into the gas zone and, consequently, affects the production mechanism and recoverable amount of reservoir gas. A strong aquifer can remarkably decrease the recovery factor in the range of 30 to 85 percent by trapping the gas phase at higher pressures $[15,16]$. As the reservoir fluid is produced, a differential pressure causes the water encroachment from gas/water contact. Large packets of gas 
may be bypassed and left behind the encroaching front; thus, the amount of residual gas saturation increment leads to the reduction of ultimate gas recovery [14].

Water production decreases the recovery by reduction of the life of the reservoir [17-19], limits productivity and efficiency of wells, and elevates safety risks in gas production. Water production can cease the well from production by water loading or make the production economically deficient. Produced water should be disposed of using proper methods resulting in a considerable increase in operational costs. It often contains large amounts of salts that require unique disposal methods and cause environmental concerns. Additionally, it may include some radioactive contents that intensify environmental effects. Eventually, even if no sign of water influx is observed during production, proper precautions should be predicted for appropriate reactions in severe conditions.

Until now, each water control method has been studied explicitly. Usually, excess water production problems are tackled regarding the severity of the issue. Generally, water production is categorized into well-based and reservoirbased issues, and well-based and easy-to-treat problems are considered first. The necessity of selecting the most proper water control method leads to the discussion of all methods in a single document. This generality enables the reader to compare different methods and efficiently select the most suitable one, and it is rarely included in previous studies. The main idea of the paper considers different aspects of the water production problem and its solution, presenting practical and field examples. This paper consists of four main parts: (1) water production sources, (2) diagnostic methods, (3) solutions, and (4) summary. In the first section, different types of water drives and various sources responsible for the water production problem in a field or a well have been introduced and discussed. The second part contains different methods to identify the water production, activity degree of an aquifer, and other factors related to water production issues. The third section is composed of two subdivisions that aim to explain solutions to the problem. The first subdivision presents reservoir-based solutions, while the second one focuses on solving the problem based on well-oriented operations. Finally, a summary of all sections has been provided. The schematic of the current approach for investigating water production is presented in Figure 1. This paper does not discuss the details of each method by itself; therefore, it is necessary to study and examine the selected methods more specifically regarding the real condition of the case under study.

\section{Water Production Sources}

2.1. Water Drive. The natural water drive is mainly categorized as follows:

(1) Limited water drive

(2) Partial water drive

(3) Active water drive
The degree of activity in aquifers differs from one reservoir to another. For instance, the reef flat gas reservoir in the Changxing-Feixianguan Formation, Sichuan basin, China, is severely active because water cut sharply increased immediately after the first water breakthrough. However, Sinian gas reservoir in Weiyuan block behaves moderately [20].

In other types of water drive, the quality of aquifer is lower, and the water-bearing portion of reservoirs does not respond to gas depletion as quickly as active water-drive aquifers. Low permeability, heterogeneity, and other possible barriers in aquifers can be responsible for this behavior. If the aquifer is not very strong and active, it does not react to hydrocarbon depletion quickly, so that the pressure drop becomes more significant and the waterfront delays in advancement toward the gas zone.

As water encroaches into the gas-bearing zone from an active water aquifer, it maintains the average reservoir pressure. In other words, it slows down the rate of pressure drop. Consequently, at abandonment conditions, the amount of gas left in the reservoir increases, and the recovery becomes considerably lower.

In some cases, there is not any aquifer in the reservoir, or it is small enough to be ignored in comparison to the portion of the gas reserve. These reservoirs are called volumetric. As more gas is produced, existing fluids and rocks will exhibit a volume change in response to pressure reduction. Since there is not a limitation for pressure reduction, it leads to larger recovery factors.

Overall, water-drive gas reservoirs are reputed to be less recoverable than volumetric reservoirs and are dependent on various conditions as follows [21]:

(1) The production rate and production approach

(2) The residual saturation of gas

(3) The properties of aquifers

(4) The efficiency of volumetric displacement of water invading the gas reservoir

A group of occurrences can be responsible for water production problems in gas fields. They can be identified from their special characteristics. Besides, these problem sources lead to low reservoir recovery and well performance, environmental impacts, and greater operational costs. They have been discussed as follows.

2.2. Coning. Water coning is one of the crucial types of water production challenges in gas fields. It is described as the mechanism underlying the upward movement of water into perforations of a production well. There are two forces that control the water coning mechanism: gravity force and dynamic flow force [22]. Relatively high drawdown pressures in gas wells may end with the water coning and the reduction of gas saturation around the well leading to the decrease of relative permeability and production of gas.

On the contrary to oil wells, a small number of studies have been performed on water coning in gas wells. Muskat [23] supposed that the physical system of water coning in gas 


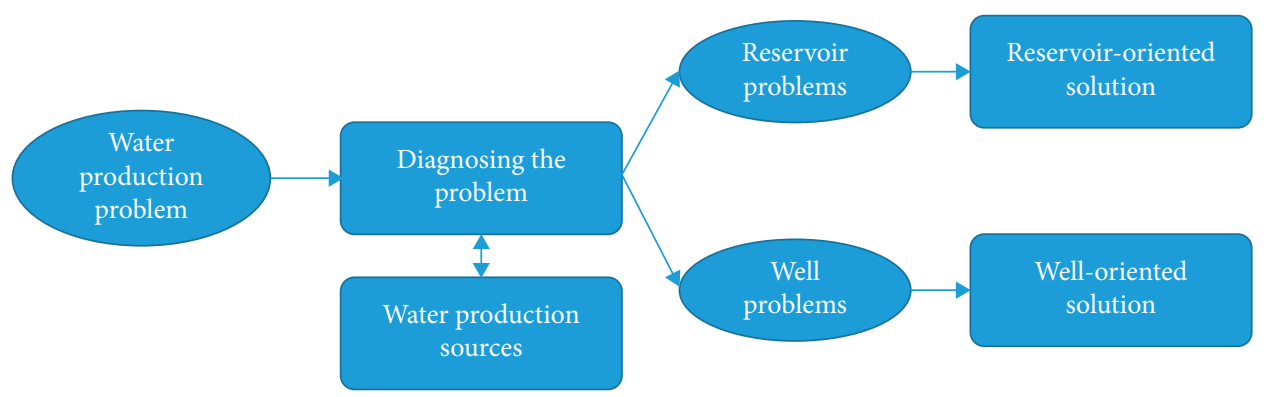

FIGURE 1: The applied approach for investigating the water production problem.

wells is similar to that in oil wells, and this phenomenon is less severe in gas wells. Trimble and DeRose [24] confirmed Muskat theory with an investigation on the Todhunters Lake Gas field, which is a moderate-to-strong water drive. On the contrary, Armenta and Wojtanowicz [22] and MacMullan and Bassiouni [25] stated that water coning in gas wells is physically different from coning in oil wells. Besides, from a numerical simulation study, Kabir [26] concluded that two parameters, permeability and pay zone thickness, are the most critical factors leading to water coning in gas fields, and other variables such as penetration ratio and production rate have minimal effect on ultimate recovery. Jafari et al. [27] executed a simulation study on one of the Iranian fractured gas reservoirs. They inferred that the well flow rate control is the most important and efficient factor to control water coning, economically and technically.

Moreover, Armenta and Wojtanowicz [22] examined the effect of vertical permeability, non-Darcian flow regime, and perforation density on water coning and the sensitivity of oil/water and gas/water systems to water influx. It was pointed out that as the vertical permeability increases, the water coning becomes more serious, and the water-to-gas ratio increases more rapidly, resulting in an early water breakthrough. Non-Darcian flows also cause further pressure drop near the wellbore that could exaggerate water coning. After all, using a modified analytic model, it was concluded that higher values of perforation density decrease the drawdown pressure and lead to lower water-to-gas ratios during production. In water-drive gas reservoirs, although a well is typically perforated at the top of the interval and produced at a limited rate, this perforation system sometimes lowers gas production rate, and it delays water breakthrough due to water coning [28].

2.3. Cresting. Similar to water coning, cresting happens when viscous forces generated by pressure drawdown defeat gravity forces associated with the density difference of gas and water [25]. This phenomenon is more common in horizontal and highly deviated gas wells. Cresting is more probable at high production rates from horizontal wells and especially near gas/water contact; thus, it is suggested the wells are drilled away from the waterfront [25]. The cresting is intensified by the increase in aquifer size and production rates, and subsequently the recovery decreases [29].
2.4. Fractures. In fractured gas reservoirs, fractures can be small, in size, or very large and deep [30]. When the formation is deeply fractured, the gas-containing zone may be connected to the aquifer; therefore, the water production problem could be extremely severe. The water penetration from fractures toward the producing zone and perforations can dramatically increase the water cut in gas wells. For instance, in Sinian gas reservoir in Weiyuan block, China, fractures are thought to be responsible for water production problems [20]. On the contrary, fractures may not be so deep, which leads to high water cut.

2.5. Water Fingering/Channeling. Sometimes there are highly permeable layers embedded between some other layers having low permeability resulting in high heterogeneity in gas reservoirs. This diversity in transmissibility of rocks leads to more advancement of water in highly permeable layers. In these layers, water advances faster due to more connected pore throats. If a well coincides with one of the mentioned highly permeable strata, an early water breakthrough and a high water-to-gas ratio occur in gas wells. For example, the Redfield storage field in Dallas is a gas reservoir in which heterogeneity causes production and recovery problems [31].

2.6. Liquid Loading. Liquid loading has been known as one of the problematic cases in gas production for many years, but its identification is not an easy task [32]. As the flow velocity of the gas in a well falls, the ability of gas to load liquids decreases.

The necessary information required for a comprehensive examination of the loading problem consists of drilling history, production data, wellbore diagram, completion log, CBL/VDL, or comparable logs necessary to evaluate cementation quality, gas and liquid sample analysis, scale and deposit analysis, and test data as well as data from production control surveys if available [33]. The provided database is analyzed to identify the reason for the liquid loading problem. Common sources of loading problems are as follows [33]:

(1) Subcritical velocity possibly in connection with water traps

(2) Increasing water-gas ratios due to coning 
(3) Increasing water-gas ratio due to (selective) water encroachment into the reservoir

(4) Production of reservoir water from water-bearing formations via poor cementation

Mahadevan et al. [34] performed some experiments to investigate the effect of temperature, pressure, and permeability on liquid loading with an evaporation mechanism. They revealed that the liquid loading intensity decreases with the increase in temperature and increases with the pressure enhancement. By comparing two samples with permeability values of 0.01 and $1 \mathrm{md}$, it was concluded that higher permeability leads to more liquid unloading by evaporation mechanism.

2.7. Substantial Pressure in Water-Invaded Zones. A deviation between the calculated and real pressure values due to substantial pressure gradient exhibiting can be a source of water production problems. Lutes et al. [35] carried out a study on Katy reservoir in Oklahoma, and they found that the problem origin is a strong water drive due to substantial pressure gradient.

\section{Diagnostic Methods}

Several methods have been presented to identify water production problems, sources of problems, and selection of proper strategies. Agrawal et al. [21] used Carter-Tracy water influx model [36] and material balance equations to study the effect of the production flow rate on the ultimate recovery of a water-drive reservoir. They solved two equations by trial and error simultaneously and obtained a relation between the cumulative gas produced and the $P / Z$ ratio. Then, they plotted cumulative gas production versus $P / Z$ ratio for each production flow rate giving the trend of ultimate recovery with changing flow rates. As the production flow rate increased, the corresponding curve got closer to the illustrative line of no water influx that is representative of the maximum recovery. Afterward, they examined the effect of aquifer permeability, initial pressure, and continuous production on recovery. It was demonstrated that as the permeability of the aquifer increases, the ultimate recovery decreases. Gas recovery is less sensitive to production rate for reasonable production rates as aquifer permeability increases. Water influx reacts so rapidly to pressure changes in the high-permeability gas reservoir. Besides, less recovery was obtained for higher initial pressures [21]. The gas recovery decreased from $81.2 \%$ of initial gas in place (IGP) for continuous production to $66.4 \%$ IGP for intermittent production. This was caused by an increase in abandonment pressure from 1,552 to 2,721 psia. Finally, they found that the gas recovery was a function of production rate, strength of aquifer and permeability, saturation of residual gas, and volumetric seep efficiency of water invading zone.

Agrawal et al. [21] also proved that a lower abandonment pressure of a reservoir and a higher water influx from an aquifer led to better recoveries. Most of the time, the type of reservoir aquifer is determined by experience and a quick review of pressure/production data. Some type curves have been presented to estimate the degree of activity of aquifer and the recovery of gas reservoirs by Li et al. based on the material balance equation [37].

Knapp et al. [31] performed a multidimensional, twophase, compressible fluid flow calculation to simulate the reservoir depletion. It was concluded that ultimate recovery in water-drive gas reservoirs is dependent on aquifer strength, production rate, fluid and rock properties, abandonment pressure of the reservoir, and especially reservoir heterogeneity. To study the effect of reservoir heterogeneity on recovery, three hypothetical reservoirs of different heterogeneities from the Redfield gas storage field, Dallas, were selected: (1) completely homogenous, (2) heterogeneous with vertical communicating, and (3) heterogeneous reservoir without vertical communication. Calculations indicated 62.5 percent recovery for homogenous reservoirs and 42.9 percent for reservoirs with vertical communications. The recovery of the noncommunicating system became 20.6 percent because the vertical flow was impeded and water fingering occurred in high permeable regions. It was pointed out that as heterogeneity increases, the recovery exhibits a decrease in water-drive gas reservoirs. In further simulation runs and calculations, Knapp et al. [31] confirmed the idea developed by Agrawal et al. [21] that recovery of gas reservoirs improves with reduction of aquifer strength and increase in gas production rates.

The existence of a substantial pressure gradient was confirmed by Lutes et al. [35] using subsequent one-dimensional numerical solutions based on the solution of partial differential equations. They applied a modified Van Everdingen and Hurst [38] unsteady-state material balance equation and finite difference techniques to describe the behavior of the Katy sand reservoir. This gradient caused an increase in pressure resulting in a reduction of the recovery, and lower pressures ahead of the waterfront influenced the deliverability of wells.

In some cases, it is difficult to estimate the original gas in place and the recovery factor because the conventional $P / Z$ method responds falsely. For instance, in the study of Pepperdine [39] on the Middle Devonian gas fields containing a large aquifer located in Canada, water encroaches into a reef formation and causes some difficulties in routine calculations. Different results were obtained where geological interpretation revealed 1910 BSCF original gas in place, and pressure decline versus cumulative production curve showed $4800 \mathrm{BSCF}$ gas in place. In the third attempt, the unsteady-state water influx equation and material balance equations were solved assuming a linear infinite aquifer resulting in $1800 \mathrm{BSCF}$ gas in place. This value confirms the results achieved by geological interpretation and misleading caused by $P / Z$ curves. Therefore, it was concluded that when there is a remarkable difference between results of geological interpretation and $P / Z$ curves, solving unsteady-state water influx and material balance equations can be helpful. Additionally, a numerical simulation was used to illustrate that overall recovery is affected by the location, distribution, and timing of development wells. 
Feng et al. [20] stated the reasons for successful water control of the second member of Xujiahe formation in Zhongba gas reservoir, which is under active edge-water drive as follows: First, some observation wells in the zone of edge-water played a key part considering the water influx direction and water body energy. Second, to hold the balanced production and control water, increasing well density helped in major water influx channel zones. Then, as signs of water influx were observed, they lowered the production rate to control water, stopping the water influx rate and opportunity for further research and control. Eventually, after clearly understanding water influx energy and direction, they utilized wells on water influx channels to drain water to lighten the effect of water influx.

An experimental investigation by Rezaee et al. [40] was conducted to study the reservoir heterogeneity effect on the recovery performance of a gas reservoir. Nitrogen with seven core samples of different heterogeneity degrees was used. The degree of heterogeneity of core samples was characterized by the Dykstra and Parsons [41] coefficient, which varies from 0 (homogenous) to 1 (heterogeneous). The range of samples varied reasonably from 0 to 1 to cover a good variety of samples. Eventually, from experimental results, it was concluded that heterogeneity is not always determinant for the recovery factor. The severity of this effect is clarified when the permeability ratio increases leading to a rise in the Dykstra-Parsons coefficient. As the Dykstra-Parsons coefficient increases, residual saturation in porous media increases too, resulting in a reduction in gas recovery of water-drive gas reservoirs.

Li et al. [37] presented a method to verify the activity level of aquifer and abandonment pressure of gas using pressure production data. The relation between coefficient of water remaining $\omega$ and reserve recovery degree $R_{g}$ was obtained in the following form:

$$
\begin{aligned}
& \ln \omega=B \ln R_{g}, \\
& \text { or } \omega=R_{g}^{B},
\end{aligned}
$$

where $\omega$ is defined as

$$
\omega=\frac{W_{e}-W_{p}}{G * B_{g i}} .
$$

For strong water influx, the value of $B$ is small, where it is very large for weak water influx conditions. It was stated that $B$ remains constant if the production strategy does not change during reservoir life. According to (1), if $B$ is equal to $1, \omega$ and $R_{g}$ are also equally showing a strong aquifer. However, if $B$ goes to infinity, $\omega$ becomes approximately zero, denoting the absence of aquifer [37]. Therefore, an aquifer exists for values of $B$ in the range of $1<B<\infty$. In cases that $B$ is greater than 4 , the effect of an aquifer can be ignored so that it can range between 1 and 4 for large aquifers [37]. Li et al. [37] also classified water-drive gas reservoirs into three categories according to the value of $B$. The aquifer is active if $B$ is in the range of $1-1.5$; it is said to be moderate if $B$ is between 1.5 and 2.5; eventually, it is inactive when $B$ ranges from 2.5 to 4 .
Neglecting the impact of compressibility, the material balance equation (MBE) of water-drive gas reservoir is

$$
\begin{aligned}
\frac{P}{Z}(1-\omega) & =\frac{P_{i}}{Z_{i}}\left(1-\frac{G_{p}}{G}\right), \\
P_{r} & =\frac{1-R_{g}}{1-\omega}, \\
P_{r} & =\frac{(P / Z)}{\left(P_{i} / Z_{i}\right)},
\end{aligned}
$$

where we have $R_{g}=\left(G_{p} / G\right)$. By substituting (4) and (5) in the following equation:

$$
P_{r}\left(1-R_{g}^{B}\right)=1-R_{g},
$$

where $P_{r}$ can be plotted versus $R_{g}$ to define theoretical curves, which are used to estimate the strength of aquifers (Figure 2).

Considering the effect of compressibility, the material balance equation is in the following form [37]:

$$
\frac{P}{Z}\left(1-C_{c} \Delta P-\omega\right)=\frac{P_{i}}{Z_{i}}\left(1-\frac{G_{p}}{G}\right),
$$

where we have $C_{c}=\left(C_{w} S w c+C_{p} / 1-S_{w c}\right)$.

Combining and manipulating the above equations give

$$
P_{r}=\frac{1-R_{g}}{1-C_{c} \Delta P-\omega} .
$$

As discussed below, a suppositional curve was also obtained by Li et al. to calculate the abandonment pressure of a gas reservoir. At each step of production, the gas reserve can be determined using the equation revealed by Agrawal et al. [21]:

$$
G_{R}=G-\frac{\left[\left(E_{v a} G B_{g i} S_{g r} / 1-S_{w c}\right)+\left(1-E_{v a}\right) G B_{g i}\right]}{B_{g a}} .
$$

By applying $S_{g i}=1-S_{w c}$, the above equation can be rearranged to achieve the proceeding equation:

$$
\frac{G_{R}}{G}=1-E_{v a}\left(\frac{S_{g r}}{S_{g i}}+\frac{1-E_{v a}}{E_{v a}}\right) \frac{\left(P_{a} / Z_{a}\right)}{\left(P_{i} / Z_{i}\right)} .
$$

Considering $E_{R}=\left(G_{R} / G\right)$ and $P_{r a}=\left(\left(P_{a} / Z_{a}\right) /\left(P_{i} / Z_{i}\right)\right)$, (10) reduces to

$$
1-E_{R}=\left[1-\left(1-\frac{S_{g r}}{S_{g i}}\right) E_{v a}\right] P_{r a} .
$$

Let $a=1-\left(S_{g r} / S_{g i}\right)$; then, we have

$$
P_{r a}=\frac{1-E_{R}}{1-a E_{v a}} \text {. }
$$

Assuming that $P_{r K}$ and $E_{R}$ are variable, the following equation is achieved:

$$
P_{r}=\frac{1-R_{g}}{1-a E_{v a}},
$$

and $P_{r}$ should be plotted against $R_{g}$, both ranging from zero to one (Figure 3). $E_{v a}$ and $a$ are known values for each 


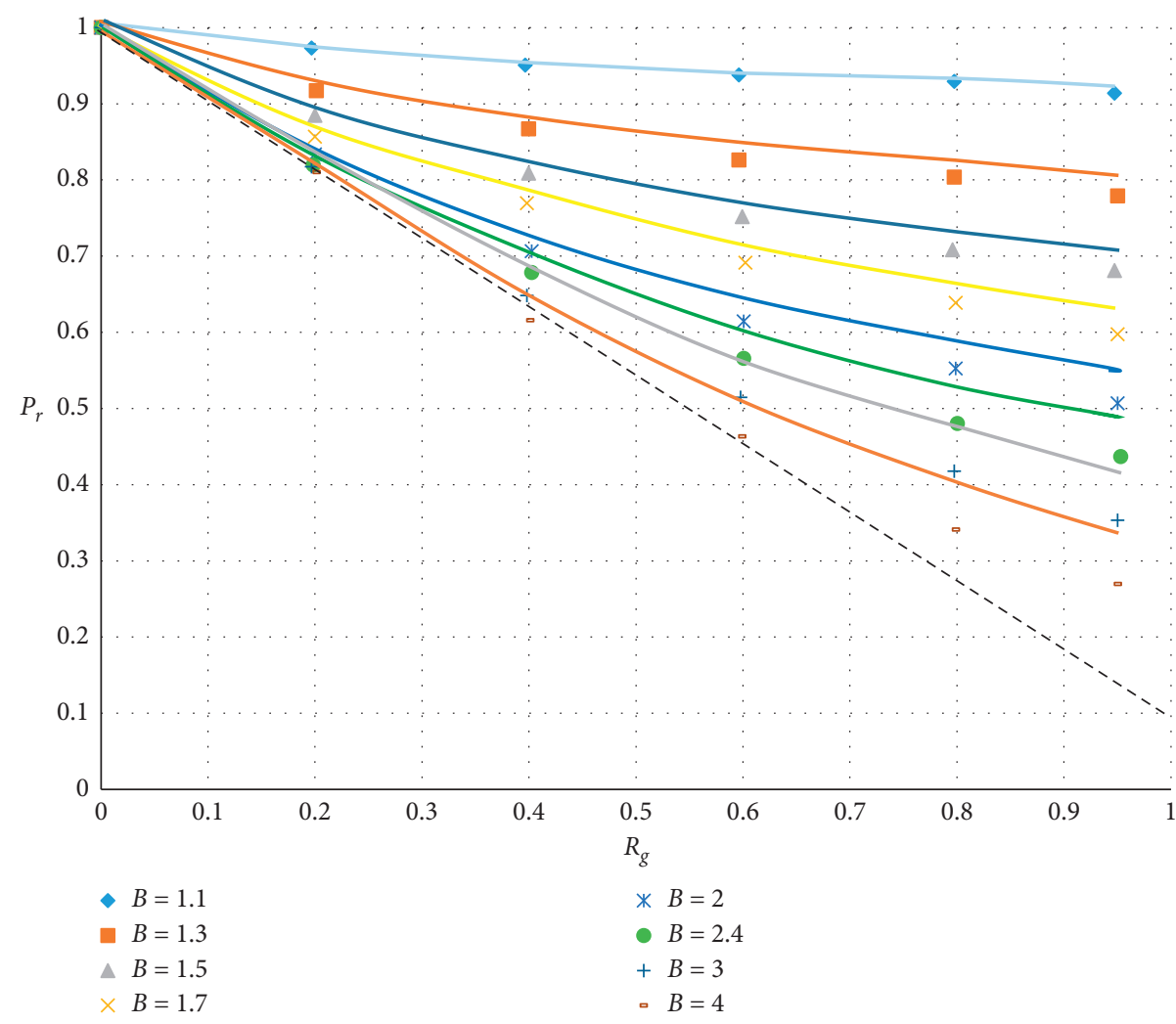

Figure 2: Type curves according to (6) [37].

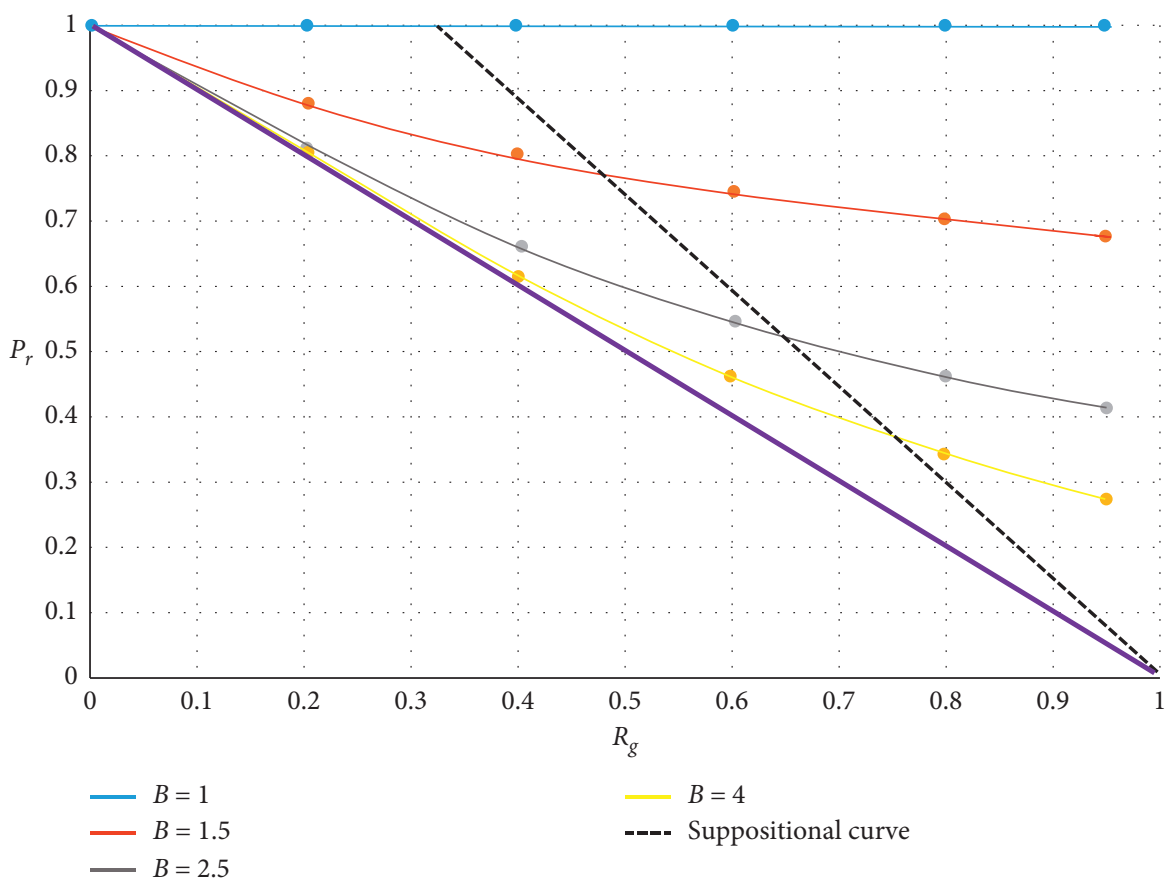

Figure 3: Plots of (6) and (12) with different $B$ values when $a=0.8$ and $E_{v a}=0.4$ [37].

reservoir. This curve is called suppositional because, in their range, only one point is real. There is a unique point that is obtained when the curve of (6) or (8) bisects the curve generated by (12), which denotes the abandonment pressure of the reservoir for a specific pattern of production. Therefore, the rest of the points are thought to be suppositional. 
Feng et al. [20] tried to explain the importance of sufficient data from an aquifer and adequate well numbers that give a better vision of what occurs under the ground. Former studies revealed that typical log-log curves achieve a good prediction of edge-water invasion efficiency [20]. Since the bottom-water-drive model is different from the edge-water, the application of the log-log curve on the bottom-water drive was unsuccessful.

A study has been done by Cheng et al. [42] on the right region of the Amu Darya gas field, which is located at the Turkmenistan border, and they tried to identify the source of water production in a gas field. The gas field has an active bottom aquifer. In the initial days of production of some wells, the mentioned reservoir conditions and their heterogeneities result in the breakthrough of various degrees that restricts their deliverability seriously. Firstly, all candidate reasons for water production were considered. Formation water, operating fluids, and condensate water are probable sources. Besides, three methods were assumed to identify the real source: physical properties and water-to-gas (WGR) ratio for the condition of a particular source; the method of chloride ion conservation for the state of multisource water production.

Physical properties and WGR are vital factors in the identification of water sources, and they are used for singlesource water problems. Condensate water has low density, low salinity, and a value of $\mathrm{pH}$ considerably less than seven due to acidic dissolution component of natural gas [42]. Operating fluids (drilling and acidizing fluids) contain a large number of additives with high density and high salinity. The drilling fluid $\mathrm{pH}$ is as high as strong alkaline solutions and for acidizing fluids is very low $[4,43-45]$. The formation water samples of the aquifer indicate that its salinity and density is between the value for condensed water and operating fluids [42].

For WGR, due to high temperature and pressure in the right region of Amu Darya, the modified Mcketta-Wehe chart was used to evaluate the content of condensate water [46]. For the operating fluid, WGR is high at the initial flowback stage and decreases rapidly in the later stages [42]. Afterward, the formation water WGR is more than that of condensate water and constantly increases throughout the reservoir life [42].

Several methods have been developed to recognize the water influx and establish an optimized method for production to get the best deliverability of wells and the highest recovery factor. However, they are not applicable in reservoirs with moderate to high degrees of heterogeneity and uncertainty. Li et al. tried to establish a more functional method using three diagnostic curves and pressure/production data for individual wells [47].

The initial diagnostic curve of water influx was created on the Agarwal-Gardner flowing material balance [48], which is diversely used to evaluate OGIP. Its vertical axis is the productivity index of the pertinent well calculated with pseudo-pressure:

$$
\frac{q}{\Delta p_{p}}=\frac{q}{p_{p i}-p_{p w f}}
$$

where

$$
p_{p}=2 \int_{0}^{p} \frac{p}{\mu Z} \mathrm{~d} p
$$

where $q$ is the production rate at present, $\mathrm{m}^{3} / \mathrm{d} ; p$ is the bottom-hole flowing pressure, $\mathrm{MPa} ; \mu$ is the gas viscosity, $\mathrm{mPa} \cdot \mathrm{s} ; Z$ is the dimensionless deviation feature; $p_{p i}$ is the initial pseudo-pressure; and $p_{p w f}$ is the bottom-hole pseudo-pressure. The horizontal axes are $2 q t_{c a} p_{i} /\left(\left(C_{t} \mu Z\right)_{i} \Delta p_{p}\right)$, where

$$
t_{c a}=\frac{\left(\mu C_{g}\right)_{i}}{q \int_{0}^{t} q(t) /\left(\mu_{\text {ave }} c_{g_{\text {ave }}}\right)},
$$

where $C_{t}$ and $C_{g}$ are the total and gas compressibility, $\mathrm{MPa}^{-1} ; t_{c a}$ is the pseudo-material balance time, dimensionless; $t$ is the production time, day; $\mu_{\text {ave }}$ is the average viscosity at the corresponding time, $\mathrm{mPa} \cdot \mathrm{s} ; c_{g_{\text {ave }}}$ is the average gas compressibility at the corresponding time, $\mathrm{MPa}^{-1}$; and the superscript $i$ is initial value.

This indicative curve should be a straight line for a volumetric gas reservoir without any support from an aquifer, and its intersection with horizontal axes gives original gas in place. The three aforementioned periods are shown in Figure 4. It reveals that as water production becomes more severe in gas wells, the diagram deviates from a straight line representing more pressure maintenance by the aquifer.

In the second diagnostic curve, flowing reservoir pressure divided by gas compressibility factor is plotted on vertical axes versus cumulative gas production (Figure 5). Furthermore, the $P / Z$ curve has been frequently used to identify characteristics of water-drive reservoirs. For volumetric reservoirs, the curve is a straight line, and the curve starts to diverge from the straight line for gas reservoirs with aquifer backing. The $P / Z$ method can identify three periods of well life in the following manner: the straight line is representative of the no aquifer influx period, the slight deviation from the straight line accounts for the early aquifer influx period, and the middle-late aquifer influx period is shown when the curve deviates rapidly to the bottom right side.

The last diagnostic method is Blasingame type curves in which normalized production rate $\left(q \Delta p_{p} * 10^{3} \mathrm{~m}^{3} /(\mathrm{d} . \mathrm{MPa})\right)$ is the vertical axis and pseudomaterial balance time $t_{c a} d$ is the horizontal axis (Figure 6). These type curves are used to calculate the original gas in place by flowing bottom-hole pressure and production flow rate data. It is obvious in Figure 6 that all type curves with different $r_{D}=r_{e} /\left(r_{w} e^{-s}\right)$-where $r_{e}$ is the drainage radius, $\mathrm{m} ; r_{w}$ is the wellbore radius, $\mathrm{m}$; and $s$ is the skin factor-converge into a line of negative slope. Blasingame curves are also applicable in the identification of three aquifer influx periods. Li et al. [47] applied the mentioned type curves on gas wells in China. After that, it was suggested that the production from wells in the primary aquifer influx period and middle-late aquifer influx should be condensed simultaneously, and the production from wells in the no 


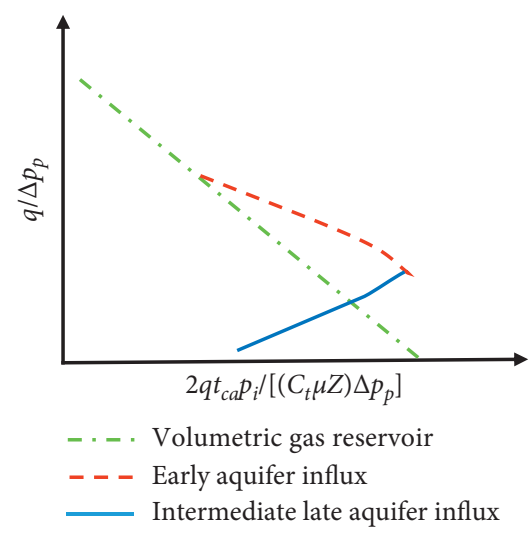

Figure 4: First diagnostic curve [47].

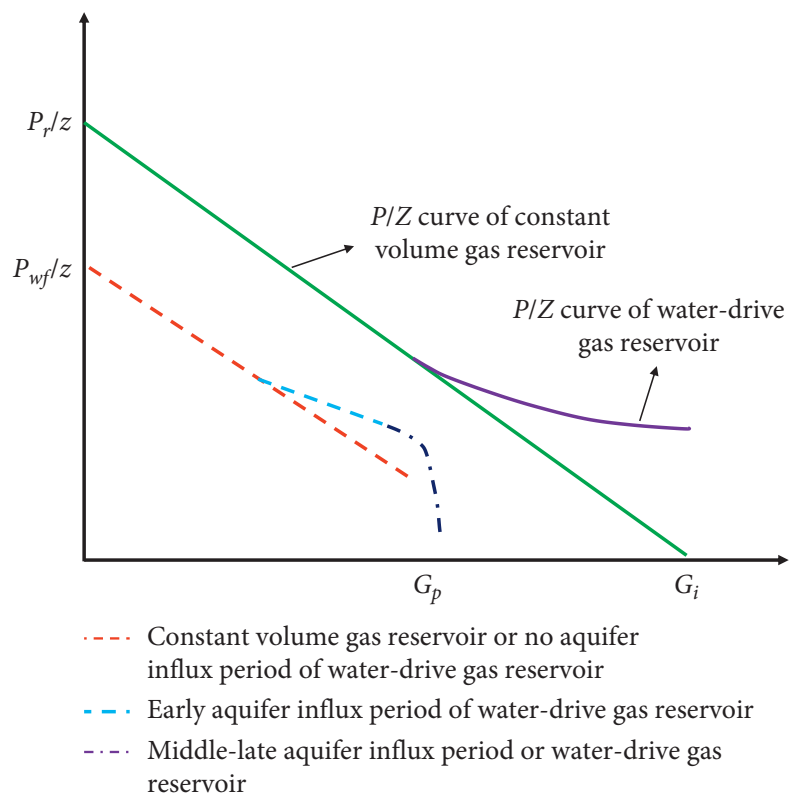

Figure 5: $P / Z$ diagnostic curve [47].

aquifer influx period should be increased to obtain the optimized production.

The liquid loading is one of the most crucial problems in gas-producing wells, and its identification is not an easy task. As the gas rises in the bore hole, the wall becomes wet by liquid droplets. For higher liquid-gas ratios, the thickness of the liquid film increases, and it becomes more stable (assuming the form of regular gas slugs moving through the rising liquid). For natural gas wells, this is usually the end of the natural unloading of liquid [49]. To tackle this problem, the calculation of the critical flow rate can be helpful [50]. These relations are based on the balance between the drag and gravitational forces that give a critical velocity of a falling particle. The critical velocity is tied to the size, shape, and density of gas and liquid; surface tension; and drag coefficient in the following shape:

$$
V_{c}=\frac{1.3 \sigma^{0.25}\left(\rho_{l}-\rho_{g}\right)^{0.25}}{C_{D} \rho_{g}^{0.5}},
$$

where $V_{c}$ is the critical velocity in $\mathrm{ft} / \mathrm{s}, \sigma$ stands for the surface tension in psia, $\rho_{l}$ and $\rho_{g}$ are the liquid and gas densities in $\mathrm{lb} / \mathrm{ft}^{3}$, respectively, and $C_{D}$ indicates the shape factor (dimensionless). Some rearrangements and manipulations on (1) give

$$
V_{c}=\frac{C\left(\rho_{l}-0.0031 P\right)^{0.25}}{(0.0031 P)^{0.5}} .
$$

Here, $C$ is $5.34 \mathrm{ft} / \mathrm{s}^{*} \mathrm{lb} / \mathrm{ft}^{3} 0.25$ for water and 4.02 for condensate. The gas will release liquids, in velocities below the critical velocity, and the accumulated liquid is calculated as follows:

$$
q_{g c}=\frac{3.06 P V_{c} A}{T Z} .
$$

Here, $q_{g c}$ is the gas flow rate in STBD and $A$ is the conduit cross-sectional area in $\mathrm{ft}^{2}$.

Perna et al. stated the advantages of this method as follows [32]:

(1) Detection of liquid loading

(2) Making a fast decision by available data

(3) Development of a relationship to compute the critical gas rate as a function of wellhead pressure

Lea et al. stated the critical flow rate in another form as follows [51]:

$$
q_{c}=1.166 * 520.1 D^{2}\left(\frac{\left(\rho_{l} z T-348.3 \gamma_{g} P\right) P^{2} \sigma}{\left(348.3 \gamma_{g}\right)^{2} T^{3} Z^{3}}\right),
$$

where $q_{c}$ is the critical gas rate, $\mathrm{Nm}^{3} / \mathrm{h} ; T$ is the in situ temperature, ${ }^{\circ} \mathrm{K} ; D$ represents the pipe diameter, in; $\gamma_{g}$ stands for the relative gas density ( $\operatorname{air}=1) ; \rho_{l}$ is the liquid density, $\mathrm{kg} / \mathrm{m}^{3} ; P$ denotes the in situ pressure, bar; and $\sigma$ is the liquid-gas surface tension, dyn/ cm. In relation to (4), the critical gas rate may be decreased, and so the unloading situations for the liquid enhanced, by [49] the following:

(1) Reduction of the pipe diameter, e.g., installation of a velocity string

(2) Reduction of the liquid density, e.g., foaming of the liquid by use of surfactants

(3) Lowering of pressure, e.g., use of compressors

(4) Increase of temperature

(5) Reduction of the surface tension, e.g., use of surfactants

\section{Solutions}

4.1. Reservoir-Oriented Solutions. Reservoir-oriented methods are mainly used to obtain better recoveries by working with pressure history and optimization of the overall reservoir flow rate. The main methods used to improve the efficiency of reservoirs are described in the next sections with field examples. 


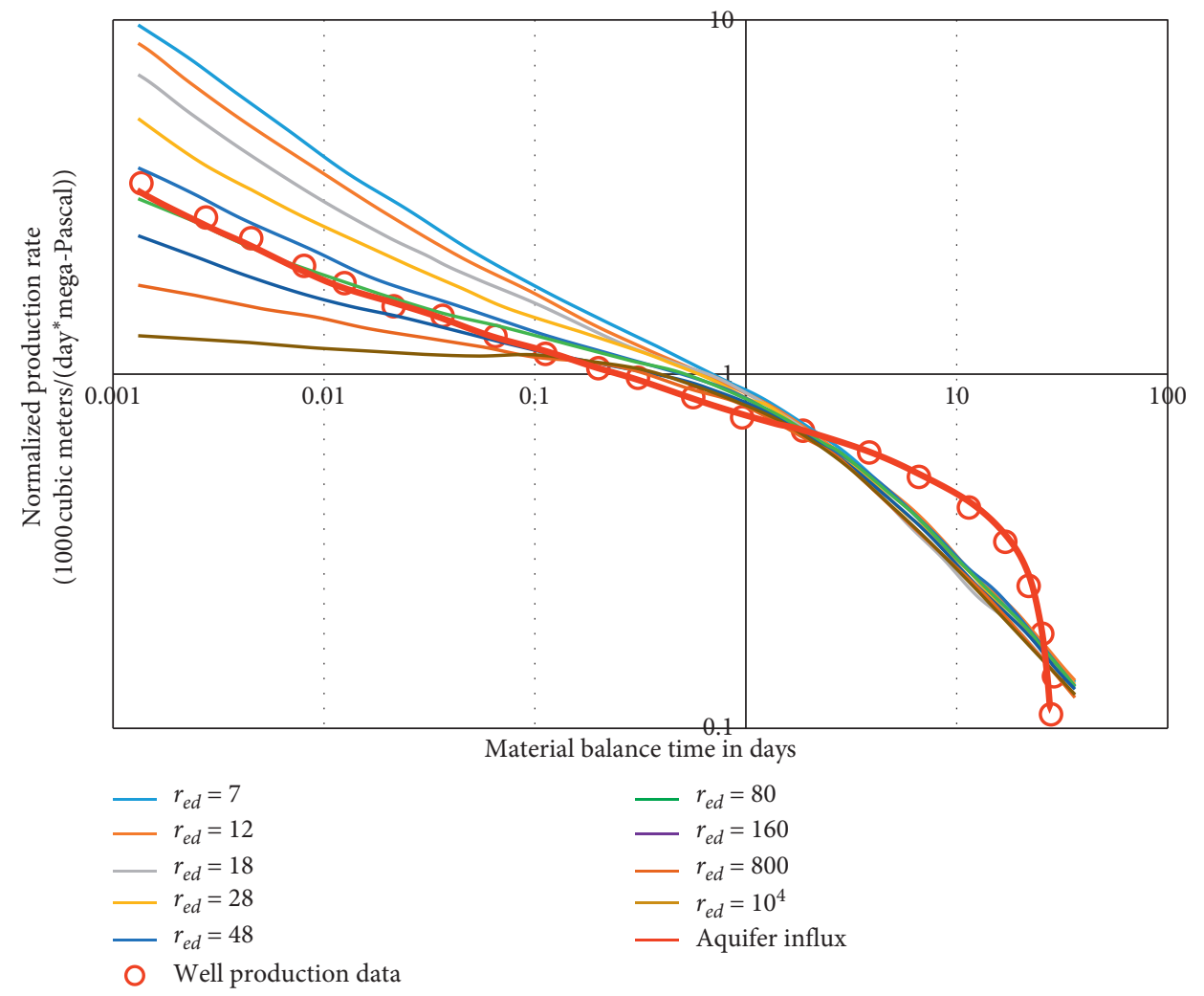

FIgURE 6: Blasingame type curves [47].

4.1.1. Coproduction Technique. Simultaneous production of water and gas to get a higher ultimate recovery factor is known as the coproduction technique which is the most technical and economical technique in the primary life of a gas reservoir $[52,53]$. This technique has been proposed for modest to active water drive gas reservoirs but has the greatest economic potential for reservoirs that are not yet watered out [14]. Lutes et al. [35] pointed out that water production can be uncommercial for strong water drive gas reservoirs. As the reservoir produces, water cut in downdip wells increases, or they become watered out, probably. The production of downdip water enhances the recovery in three aspects. Firstly, it slows down the advance of the waterfront, ending in a delay in watering out of wells. Secondly, this technique reduces reservoir pressure and, finally, decreases the pressure in the swept zone.

Arcaro and Bassiouni [52] operated on a $10300 \mathrm{ft}$ sand gas condensate reservoir in Eugene Island block 305. This reservoir contains six wells. Firstly, all production data and geological evaluations were reviewed. Secondly, volumetric analysis was applied to confirm and determine the water/gas contact. A humble material balance then was used to assess potential water production and recoveries for conventional production (without producing water) and for coproduction techniques. After that, a layered tank model, based on the material balance equation, was established, and it was adjusted with watered-out wells. Eventually, Schilthuis steady-state model [54] was originated to define the water influx. The forecasted recovery for coproduction case became 83 percent compared with 62 percent for conventional production manner, which denotes a rise of 56 BCF (from 274 BCF original gas in place) [52].

4.1.2. Accelerated Blowdown. Accelerated blowdown is a process in which the production rate of gas is increased to improve the ultimate recovery, and it is one of the widely used techniques [53]. Previous studies have demonstrated that it is one of the most appropriate techniques for strong water drive gas reservoirs [21]. When gas is produced, in an accelerated way, the aquifer delays in reacting to depletion and reduction of pressure, resulting in a higher gas recovery. Some situations may affect accelerated blowdown and limit the production program, such as lack of proper surface facilities, low deliverability of wells, economic contracts, and high permeability in the water-bearing zone. Lutes et al. [35] used a modified gas balance at six time steps, assuming that the average pressure of the invaded zone is consistent with residual gas saturation and gas saturation in the invades zone is constant. The recovery enhanced by $13 \mathrm{BCF}$ (from $330 \mathrm{BCF}$ original gas in place) applying an accelerated blowdown method, and $8.8 \mathrm{BCF}$ rose due to reduction of pressure in the invaded zone and pressure improvement of wells.

4.1.3. Optimization of Production Flow Rate. Rezaee et al. [55] stated that increasing the production flow rate does not always lead to increasing the ultimate recovery, but there is 
an optimum gas production flow rate that must be determined experimentally. In an experimental work, they used nitrogen and distilled water as two representative fluids. Firstly, core samples were saturated with water; then, nitrogen gas was injected from above to generate connate water saturation. The system was allowed to come to equilibrium for 24 hours. A dimensionless time number was obtained for the upscaling process, relating the experimental flow rate to the actual field gas production rate.

$$
\begin{gathered}
\text { Dimensionless time number }=\frac{\text { arrival pressure time to gas }- \text { water contact }}{\text { depletion time }}, \\
T_{D S}=\frac{C \varnothing \mu L^{2} q B_{g}}{12.656 \mathrm{kV}_{g}} .
\end{gathered}
$$

Five core samples with equal dimensionless time numbers had the same recovery factor with an acceptable error. In a similar experiment on one core sample, five different production rates were examined. At first, the recovery factor increased with the production rate, and then it started to reduce. From plotting recoveries versus production flow rates, and curve fitting, the maximum recovery and its pertinent production rate were calculated. Eventually, it can be pointed out that the optimum production rate for each gas reservoir should be determined experimentally. However, heterogeneity and permeability variations are some obstacles of this method in actual reservoirs because all conducted experiments were performed on homogenous core samples.

Sech et al. [29] studied the impact of the gas production rate on the recovery of a reservoir being produced with horizontal and highly deviated gas wells. Large horizontal wells can provide remarkably higher production rates compared with conventional wells. In these wells, the water breakthrough is a severe problem $[56,57]$. They found that the recovery reduces with raising of production rate for all permeability values. Moreover, obstacles of accelerating production rate decrease with increasing horizontal permeability because less drawdown pressure is needed to produce at the same rates, so that coning and cresting problems are impeded. In furthers runs, it was demonstrated that, in the lower ratios of vertical to horizontal permeability, the recovery factor is less sensitive to production rate.

4.1.4. $\mathrm{CO}_{2}$ Injection into the Transition Zone. The use of $\mathrm{CO}_{2}$ in volumetric drive reservoirs can be extended to strong water-drive reservoirs to enhance the recovery and control the water influx [14]. The density of $\mathrm{CO}_{2}$ is more than that of natural gas and less than that of water; thus, $\mathrm{CO}_{2}$ can be accommodated between gas and water zones by continuous injection into the transition zone. $\mathrm{CO}_{2}$ occupies the gap in the zone and it is expected to significantly decrease water production by changing the water drive mechanism to the complete or partial volumetric mechanism [14]. A stable displacement can be provided by the $\mathrm{CO}_{2}$ flooding, because it is more viscous and less mobile than methane gas. In fact, the $\mathrm{CO}_{2}$ expansion in the transition zone maintains the reservoir pressure, slows down the waterfront movement, and sometimes causes the water level to recede toward the aquifer, especially in weak water drive gas reservoirs [58].

Even though the $\mathrm{CO}_{2}$ injection considerably increases operating costs, the advantages of this technique can be counted as follows $[14,58-60]$ :

(1) Preventing the water encroachment from aquifers

(2) If the reservoir was invaded, the residual saturation would be from the $\mathrm{CO}_{2}$ zone

(3) Reduction of water disposal costs

(4) Enhancing the gas and condensate recoveries

(5) Pressure maintenance leading to deliverability preservation of wells

(6) In the environmental aspect, reduction of contaminations by reducing polluted water production and elimination of $\mathrm{CO}_{2}$ from the atmosphere

$\mathrm{Al}$-Hasami et al. reported that the $\mathrm{CO}_{2}$ injection after four years of production is more efficient than the injection from the first day of production [59]. Ogolo et al. established a simulation study on a lean gas reservoir with a strong water drive [14]. The $\mathrm{CO}_{2}$ injection was examined for two conditions: 30 years of production without injection and the $\mathrm{CO}_{2}$ injection from the onset of production. Seven injection wells and three production wells were used. In the case of $\mathrm{CO}_{2}$ injection, the recovery showed an increase in two wells by 11 and 17 percent and a decrease in one well by about 12 percent. The condensate recovery increased in the reservoir by 4 percent, and water production significantly decreased in all wells, except for the well having a recovery reduction. The reason for this inappropriate behavior is still unknown. The pressure was also maintained and slightly increased over the initial pressure.

4.1.5. Solving Substantial Pressure Gradient Problem in the Invaded Zone. Lutes et al. [35] used a modified Van Everdingen and Hurst [38] unsteady-state material balance equations to model substantial pressure gradient problems in water-invaded regions. They applied this method on Katy reservoir in Oklahoma and matched the pressure production performance. 
4.2. Well-Oriented Solutions. Sometimes problems can be treated in a well-based manner. If the water production source is the water influx, solutions can be stated as follows: First, if the influx has occurred due to water coning, drawdown management can be helpful. Second, if the water influx is from deeper perforation intervals and there is appropriate cementation between intervals, setting a plug can handle the problem. Eventually, cementation should be repaired, if water leaks through the cementation [49].

Liquid loading problems can be handled by consideration of the critical velocity. This requires careful production and controlling of water-gas ratio, condensate-to-gas ratio, and downhole pressure. Some sources of the liquid loading problem are mentioned before. The typical approach to handle the liquid loading is expressed in a simplified way as follows [49]:

(1) At the first signs of liquid loading, reduce the cross section to flow, e.g., by "snubbing" a velocity string.

(2) If the liquid rate is very high $\left(>50 \mathrm{~m}^{3} / \mathrm{d}\right)$, evaluate the gas lift versus pumps.

(3) For smaller liquid rates, too large for the use of plungers $\left(10-50 \mathrm{~m}^{3} / \mathrm{d}\right.$, dependent on the cross section to flow), use surfactants.

(i) Sticks in wells of shallow depth

(ii) Liquid batch applications in wells without packer

(iii) Capillary injection in wells with packer

The surfactant use requires that there is little condensate and no $\mathrm{H}_{2} \mathrm{~S}$.

(4) Otherwise, install plungers in $50-250 \mathrm{~m}^{3} / \mathrm{h}$ wells, if there is little risk of the plungers getting stuck. There are 3 types:

(i) Conventional plungers

(ii) Two-piece plungers

(iii) Multiple stages

(5) Monitor the well and lower wellhead pressure as required.

4.2.1. Artificial Lift. When the bottom-hole pressure approaches the reservoir shut-in pressure, the production stops. A general approach to repair the flow is to expel the well to the atmospheric conditions, which is called blowdown [61]. This technique releases a huge amount of methane which is environmentally and economically deficient. In order to decrease mentioned effects, some alternative artificial lift methods are normally used.

4.2.2. Foaming Agent or Surfactant. Compared to other techniques of artificial lift, foaming is one the cheapest methods [62]. According to Figure 7, it works for liquids that consist of at least 50 percent water and does not respond well to liquid hydrocarbons [61]. In shallow wells, the foaming agent is added to wells by operators through the annulus.
However, in deep wells, an injection setup is needed (surfactant tank, injection pump, motor valve, power source, and monitoring system). Lisbon and Henry reported a successful application of foaming agents in low permeability gas wells. The water production and gas-to-water ratio were both increased with this method [61].

4.2.3. Velocity Tubing. One choice to defeat the liquid loading is to set up a smaller diameter production tubing or "velocity tubing." Because the smaller diameter increases the velocity and, consequently, the lifting power, it may lower the liquid loading problem. Running a 1 in tubing string inside the production tubing in the northwest of Oklahoma and Texas Panhandle boosted the gas rate by more than $100 \%$ in four wells [63].

Ahmad and Zahoor reported a rule of thumb in a waterdrive gas reservoir; the lower completion size reduces the abandonment pressure [64]. This rule may not be true in some cases, and lowering the abandonment pressure depends on formation properties, especially permeability, aquifer strength, tubing size, flow rates, surface facilities constraints, and so on. In that case study, the maximum recovery was obtained when tubing size and production rate were brought to their maximum limit without considering any economic and facility constraints. However, the implementation of larger tubing sizes is limited with economic and facility conditions, and in the later ages of some wells, it is compulsory to use smaller tubing sizes for better water unloading.

\subsubsection{Plunger Lift Operated Manually or with Smart Well} Automation. Plunger lift is an established technique for removing liquids from aging gas wells while minimizing gas losses and methane emissions (Figure 8). The plunger lift system removes liquids from the wellbore, and it helps the well to produce at lower pressures. Production engineers consider the plunger lift to be one of the simplest forms of artificial lift because it uses the own energy of well to remove accumulated liquids and sustain the gas production [65]. This method is simple, but it can increase the chemical costs, and it is less effective if significant quantities of liquid hydrocarbon are present [61]. Brady and Morrow successfully used the plunger lift for 130 low-pressure, tight-sand gas wells with water production problems [66].

4.2.5. Pumps. Currently, it is believed that the pump is an effective and economical way for lifting a large volume of fluid from the deep well under a variety of well conditions. As Figure 9 illustrates, the pump achieves the highest efficiency when the pumped fluid is only liquid [67].

4.2.6. Intelligent Methods using ICVs. Downhole flow and pressure control can be attained through the use of interval control valves (ICVs) which are remotely controllable. Some researchers have indicated the usage and profit of intelligent wells with ICVs like Brouner and Jansen [68], Gai [69], Ajayi 


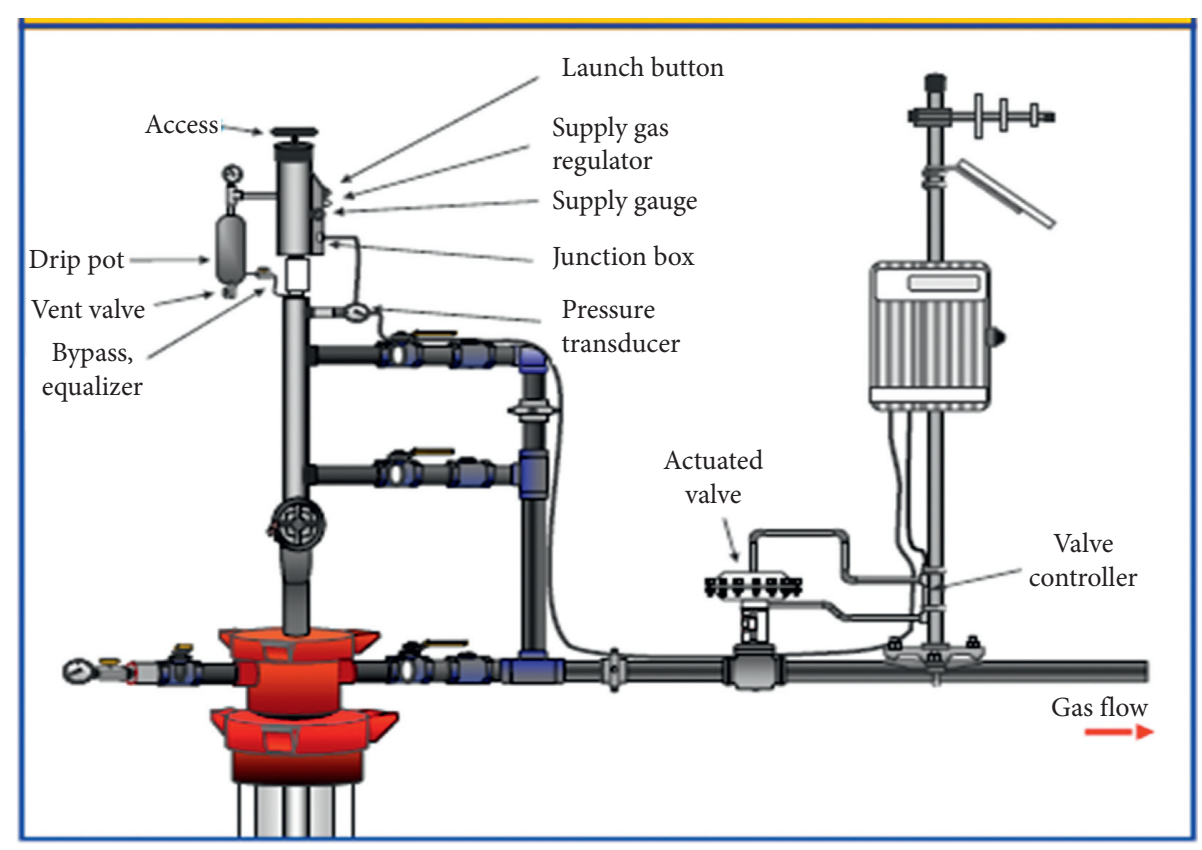

FIGURE 7: Foaming setup [61].

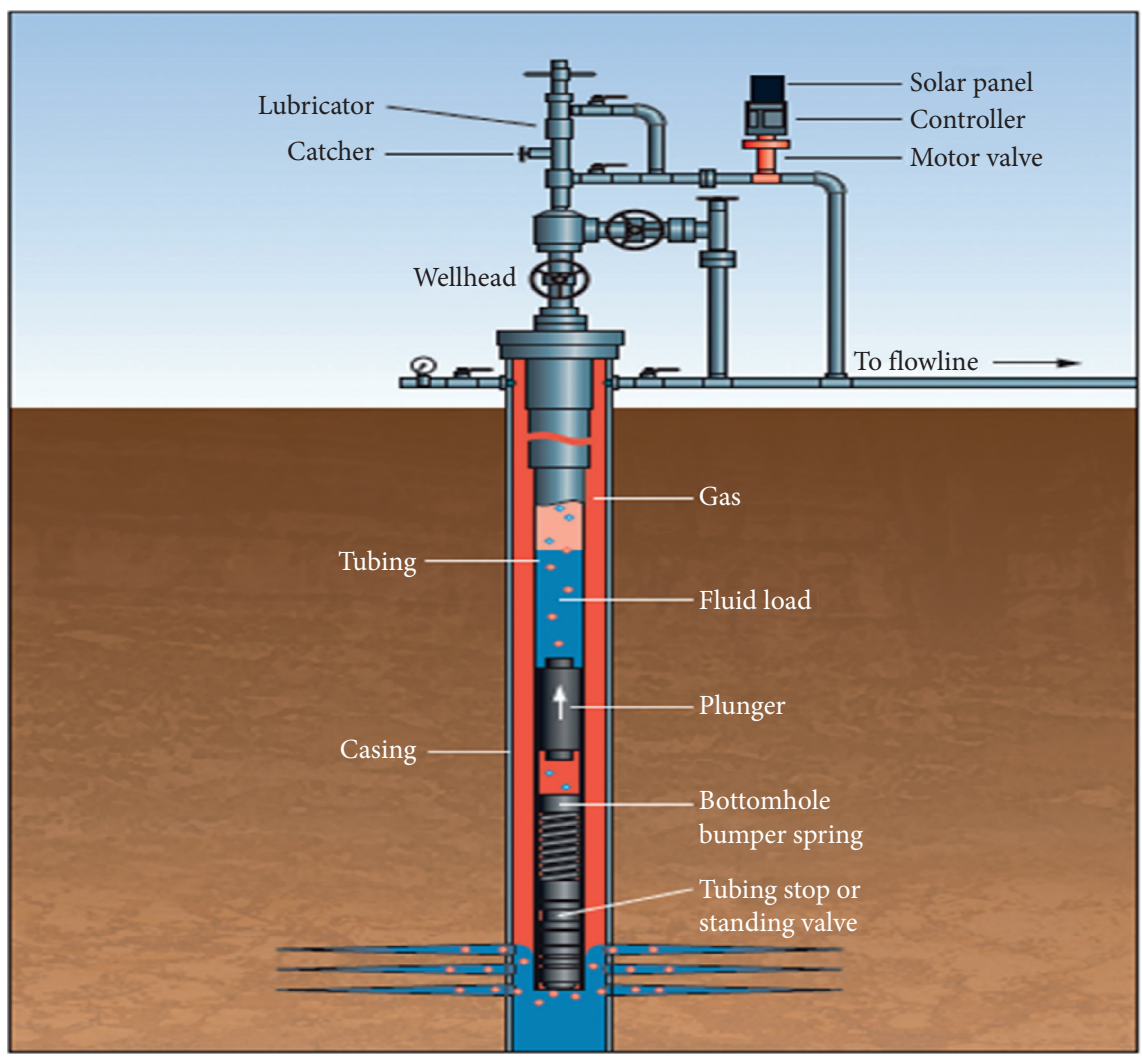

Figure 8: Plunger lift in a typical well. 


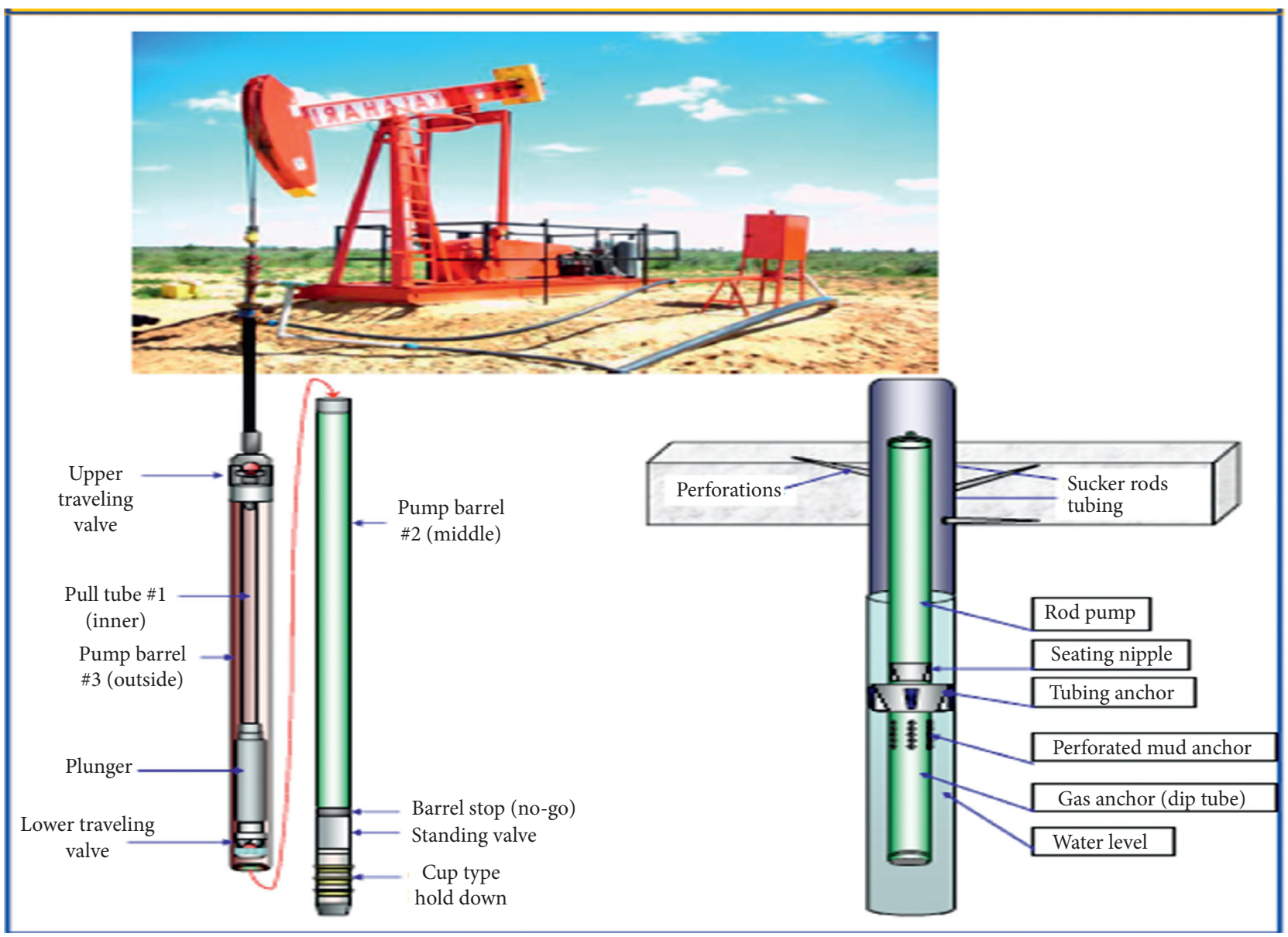

Figure 9: Positive displacement pump and rod pump [67].

and Konopczynski [70], Durlofsky and Aziz [71], and Naus al. [72].

Yamali et al. used a hybrid optimization method to optimize pressure intervals that ICVs could work with [28]. To evaluate the objective function, an approximation method was applied, called proxy model (pressure intervals are independent variables). Approximation methods were generally more cost-effective than simulation methods. Response Surface Methodology (RSM) and experimental designs were utilized to make the proxy model for performance function [28]. Besides, other techniques were tested to ensure that the proxy model concludes a valid objective function. Then, a hybrid genetic algorithm was used to optimize the objective function. Moreover, this method improves the uniqueness of the solution and is less computationally expensive.

4.2.7. Downhole Water Sink (DWS) Technology. The DWS technique uses a dual-completed wellbore in which the lower part is isolated from the upper zone by packers (Figure 10). It controls the water production by redirecting the stream of water to the bottom portion of the borehole, and as a result the performance of the top completion can be maximized. Several studies have been done to evaluate the feasibility of this method [73]. It was figured out that the DWS can boost the recovery and productivity of low-productivity gas reservoirs. The DWS and DGWS (downhole gas/water separation) both give the same recovery, but the DWS accelerates the production and produces sooner.

Armenta and Wojtanowicz stated that the best stage to begin the DWS process is in the early life of a well when the water production begins. Besides, it should not be postponed until the well is completely loaded with water. Moreover, six factors controlling DWS well performance were analyzed using a layer-cake type model to reach the best conditions by Armenta and Wojtanowicz [74].

4.2.8. Reduction of Top Completion Length. Shortening the completion increases the production period and, consequently, increases the recovery. On the other hand, increasing the completion length raises the production rate as well as water production; therefore, more water drainage from the bottom zone is required. Besides, water production should be increased gradually to continue with water invasion.

4.2.9. Downhole Gas/Water Separation (DGWS). One of the technologies introduced to tackle the water problem is downhole gas/water separation (DGWS) (Figure 11). Water and gas are separated, and water is disposed of into a nonproductive layer of the same well at downhole 


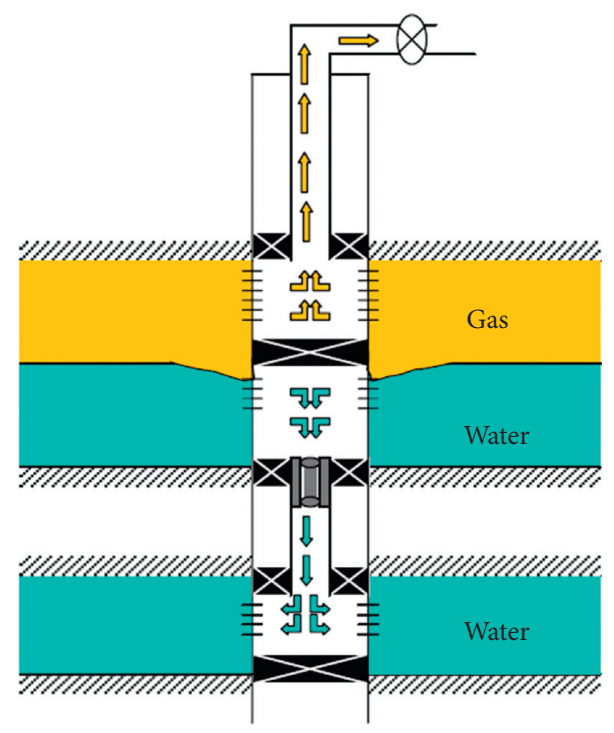

Figure 10: Downhole water sink [73].

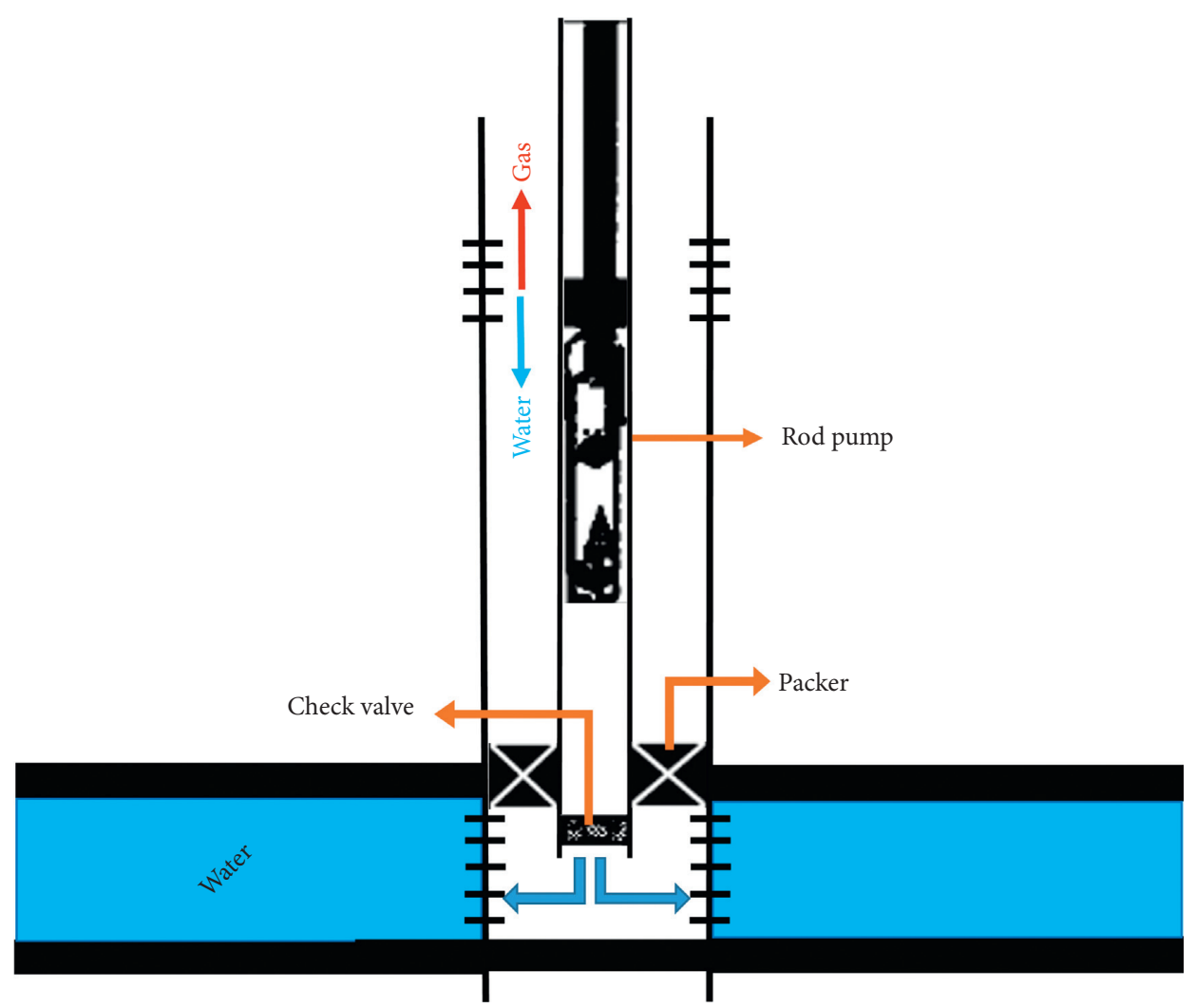

FIGURE 11: Well completion configuration in a well with the DGWS system [75].

conditions. Water is injected into disposal formations using one of the following pumping agents: modified plunger rod pumps, electrical submersible pumps, progressive cavity pumps, and insert pumps. Since the difference between densities of water and gas is high, separation naturally occurs in the borehole. The DGWS technology can be classified into two main categories: gravity separation and hydrocyclone separation [17].
The appropriate injectivity and disposal zone quality are key factors in choosing a well for the DGWS application, and the candidate reservoir should have sufficient remaining reserve. Furthermore, disposal formations must be isolated from the production zone [17]. The DGWS technology has great potential in gas well dewatering and reservoir development, especially in low-pressure/low-permeability gas reservoirs [17]. 
A Canadian company installed a special DGWS system that improved the production in comparison to other DGWS systems; moreover, some operating conditions were developed. The production was improved from 555 KSCFD gas and 440 BWPD water to 777 KSCFD and 195 BWPD in a well. Several commercially available systems were tested for injecting water into the lower disposal zone within the production well [75].

After economical and technical analysis, a "by-pass" subconfiguration pump was installed on a well in sandstone reservoir located in Alberta, Canada. The well produced water free for about 18 months. Afterwards, water production could easily be demonstrated by material balance calculations. The determination of water production source was not straightforward due to the complexity of the formation. Installation of this system caused an increase in production. In this case, despite the robust flow characteristics, the flow area was small and the additional pressure drop was caused by the liquid loading. To improve the aforementioned system, the following modifications were also suggested [75]:

(1) Installation of a larger downhole pump such as progressing cavity pump (PCP) or electrical submersible pump (ESP)

(2) Improving the downhole separation efficiency

Gao et al. reviewed 92 wells with the DGWS installation and reported that 61 percent of applications were successful [46].

4.2.10. Formation Cement Squeezing. Because this technique is available and easy to apply, it is one of the primary choices to shut-off problematic perforations, fractures, and channels [76]. Cement slurry is forced under pressure to a specific point in wells [77]. The operation is divided into two specific techniques [77]:

(1) High-pressure squeeze is used when the formation is under a cake of workover fluid. High injecting pressure fractures the formation, resulting in the usage of larger volume of cement

(2) Low-pressure squeeze does not cause the development of more fractures, so it needs less volume of cement compared with the previous technique

Some properties of well and formation, like fractures and injectivity, should be considered before applying cement squeezing. For instance, in gas condensate field of Hassi R'Mel in Algeria, which was suffering from water production through fractures, this technique failed [76]. Some possible reasons for this failure have been suggested: the possibility of formation resistance to injectivity, obstruction of perforations, and some technical reasons. Moreover, the long-term efficiency of this method is restricted in the Tunu field in Indonesia because highpressure drawdown, pressure variations, and temperature fluctuations ended with the loss of cement from perforations [78].
Moreover, this method may lead to loss of productive zone due to cementing and blocking the problematic interval. This loss is a critical disadvantage of cement squeezing approach.

4.2.11. Gas Lift. One of the candidate methods to remove the water loading is the gas lift technique (Figure 12). The high-pressure gas is injected through the casing, and a gas lift valve allows gas to produce at the surface from the tubing [79]. Water is lifted to the surface by the evaporation mechanism reducing the density of the loaded liquid in wells [79]. To test the feasibility of this method for each well, further economic evaluation is needed [80].

4.2.12. Bridge Plugs. This equipment is used to isolate the water-producing interval in gas wells. It is set with two methods: electric wireline and mechanical methods. Two types of bridge plugs are common: retrievable and permanent. Retrievable plugs can be removed and installed several times, but permanent plugs cannot be used again. Permanent types can be removed by drilling. Bridge plugs are used when the problematic zone is below the producing zone, in other words, when there is no productive interval below the water-producing zone [78]. If there is a gas-producing zone below the problematic interval, using bridge plugs results in the loss of valuable intervals, and less gas is produced [78].

4.2.13. Polymer Treatment. In some cases, it is difficult to distinguish exact boundaries between gas- and water-producing intervals, and the usage of permanent plugs is very risky [81]. Therefore, it is more desirable to use selective barriers that block water and transmit gas by using hydrosoluble polymers [82]. The relative permeability of brine is remarkably reduced due to polymer adsorption on the surface of rock [81]. In addition, the reversible adsorption of polymer aids the long-term efficiency of this method [83] (Figure 13).

The efficiency of this process is severely dependent on the thickness of the absorbing layer in comparison to the pore size [83]. In fractured and high permeable reservoirs, water flows through channels and remarkably reduces polymer efficiency [81, 84]. To tackle this problem, some metal ions (crosslinkers) are used to make a polymer network [85].

Dovan and Hutchins reported an application of a polymer crosslinked with titanium in a gas reservoir in Northern California. The polymer contained potassium bicarbonate to retrieve the gas permeability by evolving $\mathrm{CO}_{2}$, but both gas and water production reduced. In order to restore the gas permeability, HCL was injected into the formation. It was expected that acid fingers polymer gel, but water production increased again bringing the gas permeability back to its previous state. Therefore, it was concluded that polymer gel could be removed partially or completely by acidizing. In 1988, another well in Northern California was treated with polymer. Ester was injected with crosslinking material and potassium bicarbonate to restore the gas permeability by a chemical reaction (evolving $\mathrm{CO}_{2}$ ). The 


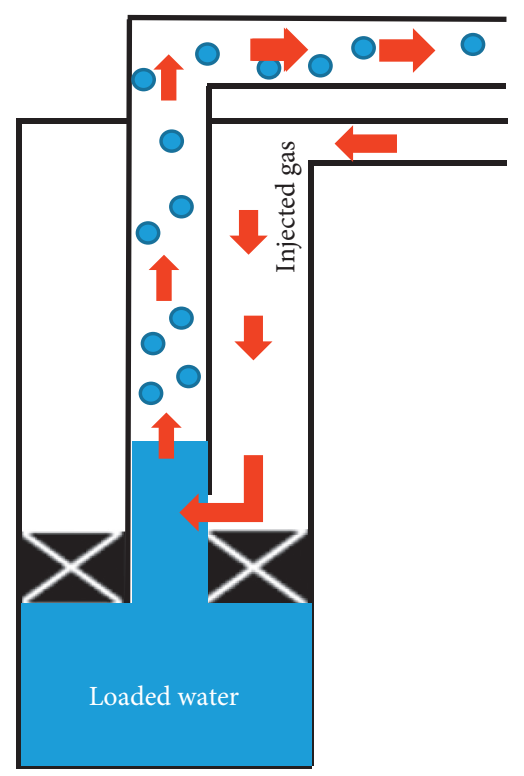

Figure 12: Dewatering of a gas well by gas lift technique [80].

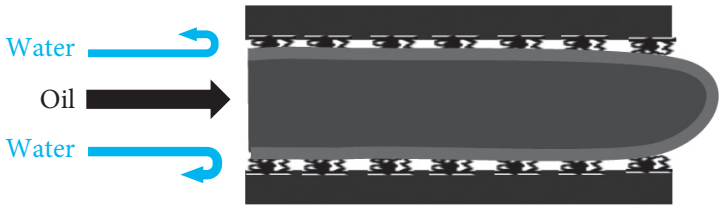

(a)

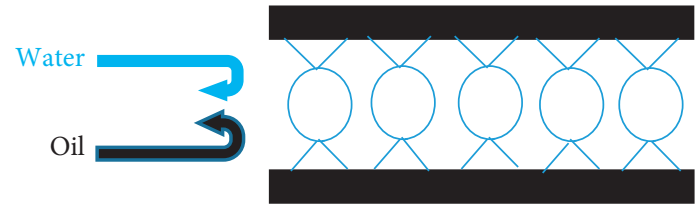

(b)

Figure 13: Single polymer treatment and crosslinkers [81]: (a) polymer adsorption; (b) crosslinked polymer.

process was successful, and water production decreased simultaneously with improving the gas relative permeability.

Zaitoun et al. established an experiment to examine two types of polymer for reservoirs with low and high salinities [81]. Polymer A swelled in high salinity and shrank in low salinity, and the opposite was true for polymer B. Polymer A was injected in saltier water than reservoir brine. It was absorbed on the surface of the rock during the injection. Polymer particles swelled when they were exposed to brine, and consequently it blocked the flow of water in the reservoir. The process corresponding to polymer B was exactly the opposite. For the first time in a gas field, in 1986, polymer A was injected into the Cerville-Velaine sandstone reservoir. Water production in wells significantly reduced, and its effect remained for a long time.

A core flood experiment of polymer B was performed by Zaitoun and Pichery to examine polymer injection into the Saint-Clair-sur-Epte reservoir [86]. It was a limestone reservoir associated with a strong bottom aquifer. After the polymer treatment (core scale), the relative permeability of water considerably decreased without any significant change in the relative permeability of gas. In real field injection, water cut of the well remained high for two years. After that, it decreased sharply and remained at low levels for over ten years.

\section{Summary and Conclusions}

There are several studies in literature revealing various results that are acceptable technically and economically for specific cases of study. In order to choose the best solution, precise study and data analysis should be made like evaluating rock and fluid data, reviewing pressure/production performance, and considering geological aspects. After considering all aspects of reservoir and analyzing the data, the most appropriate method should be used. All mentioned possible sources, diagnostic tools, and solutions for water production problems in gas fields are summarized as follows:

(1) There are various sources for water production problems, including water drive of aquifer, coning, cresting, fractures, water fingering/channeling, liquid loading, and substantial pressure.

(2) To identify the problem source, several approaches have been developed: cumulative gas production versus $P / Z$ plot, numerical simulation (a modified Van Everdingen-Hurst unsteady-state material balance equation), Pi versus $\mathrm{Rg}$ plot, suppositional curve in $\mathrm{Pi}$ versus $\mathrm{Rg}$, well test log-log curves for water invasion efficiency, Agarwal-Gardner diagnostic curve, and Blasingame type curves. 
(3) Once the source has been diagnosed, the appropriate practical solution should be implemented. Practical solutions to tackle the water production problems in gas reservoirs are categorized into two types: reservoir-oriented solutions and well-oriented solutions.

(4) Reservoir-oriented solutions comprise coproduction technique, accelerated blowdown, optimization of production flow rate, $\mathrm{CO}_{2}$ injection into transition zone, and solving substantial pressure gradient problem.

(5) Well-oriented solutions include artificial lift, foaming agent or surfactant, velocity tubing, plunger lift, pump, intelligent methods using ICVs, downhole water sink (DWS), reduction of top completion length, downhole gas/water separation (DGWS), formation cement squeezing, gas lift, bridge plugs, and polymer treatment.

The results of this research present the basic road map for future studies in dealing with water production problems in gas reservoirs. However, several gaps still exist in the details of mechanisms and solutions. Hence, future research can focus on these existing gaps.

\section{Abbreviations}

CBL/VDL: Cement bond logging/variable density logging

IGP: Initial gas in place

BSCF: Billion standard cubic feet

WGR: Water-to-gas

OGIP: $\quad$ Original gas in place

A: $\quad$ Conduit cross-sectional area, $\mathrm{ft}^{2}$

$B: \quad$ Water influx coefficient

$B_{g a}: \quad$ Gas formation volume factor at abandonment pressure, $\mathrm{m}^{3} /$ std $\mathrm{m}^{3}$

$B_{g i}$ : Gas formation volume factor at pressure $P_{i}$, $\mathrm{m}^{3} /$ std $\mathrm{m}^{3}$

$B_{w}$ : Water formation volume factor at pressure $P_{i}$, $\mathrm{m}^{3} / \mathrm{std} \mathrm{m}^{3}$

$C_{D}: \quad$ Shape factor, dimensionless

$C_{t}: \quad$ Total compressibility

$C_{g}: \quad$ Total and gas compressibility, $\mathrm{MPa}^{-1}$

$c_{g_{\text {ave }}}$ : $\quad$ Average gas compressibility at corresponding time, $\mathrm{MPa}^{-1}$

$C_{c}$ : Compressibility of reservoir volume, $\mathrm{MPa}^{-1}$

$C_{w}: \quad$ Compressibility of water, $\mathrm{MPa}^{-1}$

$\mathrm{C}_{p}: \quad$ Compressibility of rock, $\mathrm{MPa}^{-1}$

D: $\quad$ Pipe diameter, in

$E_{v a}$ : $\quad$ Ultimate volumetric sweep efficiency at abandonment pressure, dimensionless fraction

$G_{p}$ : $\quad$ Cumulative gas produced, $\mathrm{m}^{3}$

$G_{R}: \quad$ Recoverable reserve, $\mathrm{m}^{3}$

$G$ : $\quad$ Original gas in place, $\mathrm{m}^{3}$

$P: \quad$ Pressure, $\mathrm{MPa}$

$P_{i}: \quad$ Initial reservoir pressure, $\mathrm{MPa}$

$P_{r}: \quad$ Relative pressure, dimensionless

$p_{p i}: \quad$ Initial pseudo-pressure

$p_{p w f}: \quad$ Bottom-hole pseudo-pressure

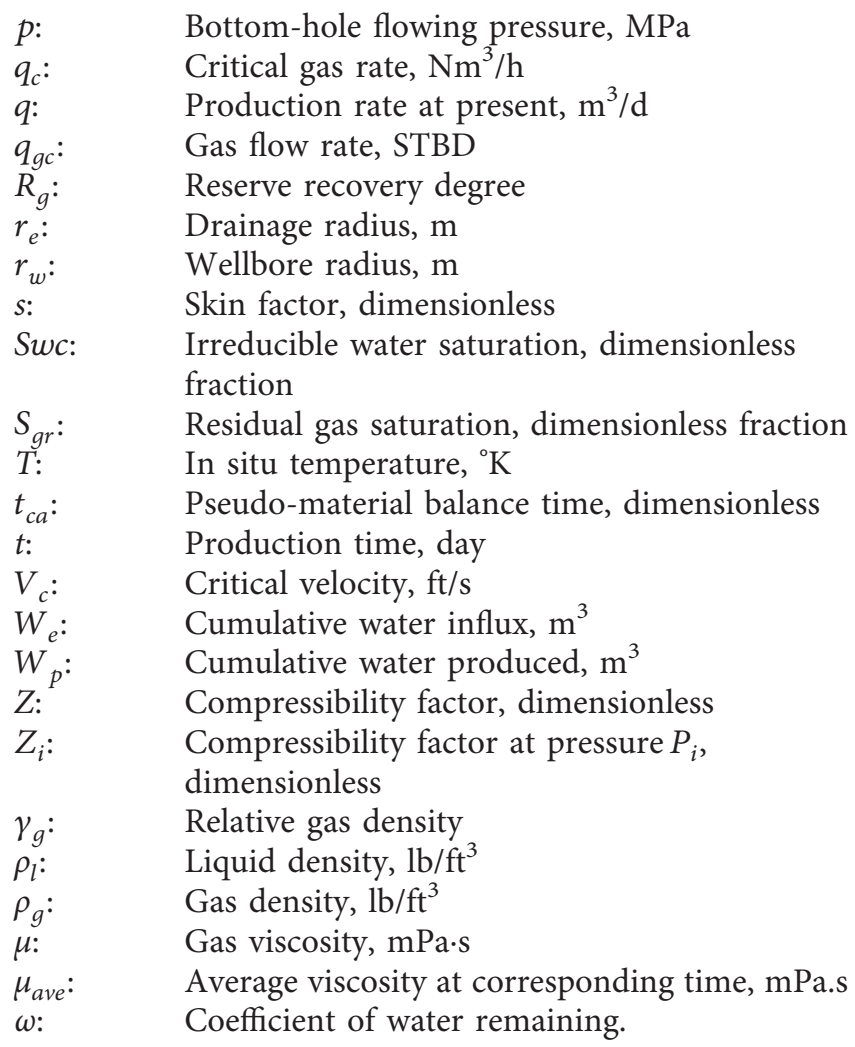

\section{Data Availability}

The data used to support the findings of this study are included within the article.

\section{Conflicts of Interest}

The authors declare that they have no conflicts of interest.

\section{References}

[1] H. Esfandyari, S. R. Shadizadeh, F. Esmaeilzadeh, and A. Davarpanah, "Implications of anionic and natural surfactants to measure wettability alteration in EOR processes," Fuel, vol. 278, p. 18392, 2020.

[2] M. Mohajeri, M. Hemmati, and A. S. Shekarabi, "An experimental study on using a nanosurfactant in an EOR process of heavy oil in a fractured micromodel," Journal of Petroleum Science and Engineering, vol. 126, pp. 162-173, 2015.

[3] R. Abdollahi and S. R. Shadizadeh, "Experimental investigation of side effect of henna extract as a new and ecofriendly corrosion inhibitor on acid injectivity of calcareous sandstone," Transport in Porous Media, vol. 97, pp. 105-118, 2013.

[4] R. Abdollahi and S. R. Shadizadeh, "Effect of acid additives on anticorrosive property of henna in regular mud acid," Scientia Iranica, vol. 19, pp. 1665-1671, 2012.

[5] M. Dong, Q. Liu, and A. Li, "Displacement mechanisms of enhanced heavy oil recovery by alkaline flooding in a micromodel," Particuology, vol. 10, pp. 298-305, 2012.

[6] H. Amani, "Study of enhanced oil recovery by rhamnolipids in a homogeneous 2D micromodel," Journal of Petroleum Science and Engineering, vol. 128, pp. 212-219, 2015. 
[7] T. N. C. Dantas, V. C. Santanna, T. T. C. Souza, C. R. S. Lucas, A. A. Dantas Neto, and P. T. P. Aum, "Microemulsions and nanoemulsions applied to well stimulation and enhanced oil recovery (EOR)," Brazilian Journal of Petroleum and Gas, vol. 12, pp. 251-265, 2019.

[8] A. Keykhosravi, M. B. Vanani, A. Daryasafar, and C. Aghayari, "Comparative study of different enhanced oil recovery scenarios by silica nanoparticles: an approach to time-dependent wettability alteration in carbonates," Journal of Molecular Liquids, vol. 324, p. 115093, 2021.

[9] O. Massarweh and A. S. Abushaikha, "The use of surfactants in enhanced oil recovery: a review of recent advances," Energy Reports, vol. 6, pp. 3150-3178, 2020.

[10] J. Foroozesh and S. Kumar, "Nanoparticles behaviors in porous media: application to enhanced oil recovery," Journal of Molecular Liquids, vol. 316, p. 113876, 2020.

[11] H. Esfandyari, A. Moghani Rahimi, F. Esmaeilzadeh, A. Davarpanah, and A. H. Mohammadi, "Amphoteric and cationic surfactants for enhancing oil recovery from carbonate oil reservoirs," Journal of Molecular Liquids, vol. 322, p. $114518,2020$.

[12] H. Esfandyari, A. Moghani, F. Esmaeilzadeh, and A. Davarpanah, "A laboratory approach to measure carbonate rocks' adsorption density by surfactant and polymer," Mathematical Problems in Engineering, vol. 2021, Article ID 5539245, 7 pages, 2021.

[13] R. Abdollahi, M. Nadri, H. Gholghanddashti, M. Safari, and M. Zare Reisabadi, "A stepwise approach for identification of water production mechanisms in gas reservoirs," Energy Sources, Part A: Recovery, Utilization, and Environmental Effects, 2021.

[14] N. A. Ogolo, J. O. Isebor, and M. O. Onyekonwu, "Feasibility study of improved gas recovery by water influx control in water drive gas reservoirs," in Proceedings of the SPE Nigeria Annual International Conference and Exhibition, Lagos, Nigeria, August 2014.

[15] T. M. Geffen, D. R. Parrish, G. W. Haynes, and R. A. Morse, "Efficiency of gas displacement from porous media by liquid flooding," Journal of Petroleum Technology, vol. 4, pp. 29-38, 1952.

[16] D. K. Keelan and V. J. Pugh, "Trapped-gas saturations in carbonate formations," SPE Journal, vol. 15, pp. 149-160, 1975.

[17] M. F. Radwan, "Feasibility evaluation of using downhole gaswater separation technology in gas reservoirs with bottom water," in Proceedings of the SPE Middle East Oil \& Gas Show and Conference, Manama, Bahrain, March 2017.

[18] M. Wei, K. Ren, Y. Duan, Q. Chen, and M. Dejam, "Production decline behavior analysis of a vertical well with a natural water influx/waterflood," Mathematical Problems in Engineering, vol. 2019, Article ID 1683989, 9 pages, 2019.

[19] I. B. Obot, S. A. Umoren, and N. K. Ankah, "Pyrazine derivatives as green oil field corrosion inhibitors for steel," Journal of Molecular Liquids, vol. 277, pp. 749-761, 2019.

[20] X. Feng, B. Zhong, X. Yang, and H. Deng, "Effective water influx control in gas reservoir development: problems and countermeasures," Natural Gas Industry B, vol. 2, pp. 240246, 2015.

[21] R. G. Agarwal, R. Al-Hussainy, and H. J. Ramey, “The importance of water influx in gas reservoirs," Journal of Petroleum Technology, vol. 17, pp. 1336-1342, 1965.

[22] M. Armenta and A. Wojtanowicz, "Severity of water coning in gas wells," in Proceedings of the SPE Gas Technology Symposium, Calgary, Canada, April 2002.
[23] M. Muskat, "The flow of homogeneous fluids through porous media," Soil Science, vol. 46, p. 169, 1938.

[24] A. E. Trimble and W. E. DeRose, "Field application of waterconing theory to todhunters lake gas field," Journal of Petroleum Technology, vol. 29, pp. 552-560, 1977.

[25] J. H. McMullan and Z. Bassiouni, "Optimization of gas-well completion and production practices," in Proceedings of the SPE International Petroleum Conference and Exhibition in Mexico, Villahermosa, Mexico, February 2000.

[26] C. S. Kabir, "Predicting gas well performance coning water in bottom-water-drive reservoirs," in Proceedings of the SPE Annual Technical Conference and Exhibition, San Francisco, CA, USA, October 1983.

[27] I. Jafari, S. Jamshidi, and M. Masihi, "Investigating the mechanism of water inflow in gas wells in fractured gas reservoirs and designing a controlling method," in Proceedings of the SPE International Production and Operations Conference \& Exhibition, Doha, Qatar, May 2012.

[28] N. Yamali, Q. P. Nguyen, and S. Srinivasan, "Optimum control of unwanted water production in stratified gas reservoirs," in Proceedings of the Production and Operations Symposium, Oklahoma City, OK, USA, March 2007.

[29] R. P. Sech, M. D. Jackson, and G. Hampson, "Controls on water cresting in high productivity horizontal gas wells," in Proceedings of the EUROPEC/EAGE Conference and Exhibition, London, UK, June 2007.

[30] R. Abdollahi, H. Esfandyari, M. Nadri Pari, and A. Davarpanah, "Conventional diverting techniques and novel fibr-assisted self-diverting system in carbonate reservoir acidizing with successful case studies," Petroleum Research, 2021.

[31] R. M. Knapp, J. H. Henderson, J. R. Dempsey, and K. H. Coats, "Calculation of gas recovery upon ultimate depletion of aquifer storage," Journal of Petroleum Technology, vol. 20, pp. 1129-1132, 1968.

[32] M. Perna, G. Bartolotto, R. Latronico, and R. Sghair, "Dynamic surveillance templates for reservoir management: diagnostic tools oriented to production optimization," in Proceedings of the International Petroleum Technology Conference, Doha, Qatar, December 2009.

[33] E. Adaze, A. Al-Sarkhi, H. M. Badr, and E. Elsaadawy, "Current status of CFD modeling of liquid loading phenomena in gas wells: a literature review," Journal of Petroleum Exploration and Production Technology, vol. 9, pp. 1397-1411, 2019.

[34] J. Mahadevan, M. M. Sharma, and Y. C. Yortsos, "Evaporative cleanup of water blocks in gas wells," SPE Journal, vol. 12, pp. 209-216, 2007.

[35] J. L. Lutes, C. P. Chiang, R. H. Rossen, and M. M. Brady, "Accelerated blowdown of a strong water-drive gas reservoir," Journal of Petroleum Technology, vol. 29, pp. 1533-1538, 1977.

[36] R. D. Carter and G. W. Tracy, "An improved method for calculating water influx," Transactions AIME, vol. 219, pp. 415-417, 1960.

[37] M. Li, W. J. Yang, Q. Y. Xiao, S. C. Liu, J. Zhang, and G. M. Peng, "Determination of the aquifer activity level and the recovery of water drive gas reservoirs," in Proceedings of the North Africa Technical Conference and Exhibition, Cairo, Egypt, February 2010.

[38] A. F. Van Everdingen and W. Hurst, "The application of the laplace transformation to flow problems in reservoirs," Journal of Petroleum Technology, vol. 1, pp. 305-324, 1949. 
[39] L. Pepperdine, "Recognition and evaluation of water drive gas reservoirs," in Proceedings of the Annual Technical Meeting, Calgary, Canada, June 1978.

[40] M. Rezaee, B. Rostami, and P. Pourafshary, "Heterogeneity effect on non-wetting phase trapping in strong water drive gas reservoirs," Journal of Natural Gas Science and Engineering, vol. 14, pp. 185-191, 2013.

[41] H. Dykstra and R. L. Parsons, The Prediction of Oil Recovery by Waterflooding in Secondary Recovery of Oil in the United States, API, Washington, DC, USA, 2nd edition, 1950.

[42] Y. Cheng, L. Mu, E. Zhu et al., "Water producing mechanisms of carbonate reservoirs gas wells: a case study of the right bank field of Amu Darya, Turkmenistan," Petroleum Exploration and Development, vol. 44, pp. 89-96, 2017.

[43] R. Abdollahi and S. R. Shadizadeh, "The effect of spent acid on carbonate rock wettability during a matrix acidizing treatment," Petroleum Science and Technology, vol. 32, pp. 450454, 2014.

[44] S. Kafashi, R. Taghdimi, and G. Karimi, "Modification of nano clay systems: an approach to stabilizing drilling fluids," $A d$ vanced Materials Research, vol. 829, pp. 818-824, 2014.

[45] S. Kafashi, M. R. Rasaei, and G. R. Karimi, "Experimental study of nanoclay absorbents and additives' effects on modification of rheological properties of drilling fluids in porous media using glass micromodel," Journal of Porous Media, vol. 23, no. 6, pp. 627-639, 2020.

[46] C. Gao, M. Rivero, E. Nakagawa, and G. Sanchez, "Downhole separation technology-past, present and future," The APPEA Journal, vol. 47, pp. 283-292, 2007.

[47] Y. Li, B. Li, J. Xia, J. Zhang, K. Guo, and Y. Hu, "New methodology for aquifer influx status classification for single wells in a gas reservoir with aquifer support," Journal of Natural Gas Geoscience, vol. 1, pp. 407-411, 2016.

[48] R. G. Agarwal, D. C. Gardner, S. W. Kleinsteiber, and D. D. Fussell, "Analyzing well production data using combined-type-curve and decline-curve analysis concepts," SPE Reservoir Evaluation \& Engineering, vol. 2, pp. 478-486, 1999.

[49] K. M. Reinicke, G. Hueni, N. Liermann, J. Oppelt, P. Reichetseder, and W. Unverhaun, "Oil and gas, 7. production," in Ullmann's Encyclopedia of Industrial Chemistry, Wiley-VCH, Weinheim, Germany, 2014.

[50] R. G. Turner, M. G. Hubbard, and A. E. Dukler, "Analysis and prediction of minimum flow rate for the continuous removal of liquids from gas wells," Journal of Petroleum Technology, vol. 21, pp. 1475-1482, 1969.

[51] S. C. Lea, G. Landini, and A. D. Walmsley, "Ultrasonic scaler tip performance under various load conditions," Journal of Clinical Periodontology, vol. 30, pp. 876-881, 2003.

[52] D. P. Arcaro and Z. Bassiouni, "Technical and economic feasibility of enhanced gas recovery in the eugene island field by use of the coproduction technique," Journal of Petroleum Technology, vol. 39, pp. 585-590, 1987.

[53] M. Z. Reza Abdollahi, M. N. Pari, S. M. Motahhari, and M. S. Reisabadi, "Fast approach to manage depletion of naturally fractured carbonate gas reservoir with water rising issue through fracture networks," Petroleum \& Coal Journal, vol. 63, pp. 387-398, 2021.

[54] R. J. Schilthuis, "Active oil and reservoir energy," Transactions AIME, vol. 118, pp. 33-52, 1936.

[55] M. Rezaee, B. Rostami, M. S. Zadeh, and M. Mojarad, "Experimental determination of optimized production rate and its upscaling analysis in strong water drive gas reservoirs," in Proceedings of the International Petroleum Technology Conference, Beijing, China, March 2013.
[56] P. J. Lumsden, C. J. Balgobin, D. Bodnar et al., "The kapok field-a step change for trinidad gas developments," in Proceedings of the SPE Gas Technology Symposium, Calgary, Canada, April 2002.

[57] R. P. Sutton, S. A. Cox, E. Glynn Williams, R. P. Stoltz, and J. V. Gilbert, "Gas well performance at subcritical rates," in Proceedings of the SPE Production and Operations Symposium, Oklahoma City, OK, USA, March 2003.

[58] J. A. C. Lopez, "Gas injection as a method for improved recovery in gas-condensate reservoirs with active support," in Proceedings of the SPE International Petroleum Conference and Exhibition in Mexico, Villahermosa, Mexico, February 2000.

[59] A. Al-Hasami, S. Ren, and B. Tohidi, " $\mathrm{CO}_{2}$ injection for enhanced gas recovery and geo-storage: reservoir simulation and economics," in SPE Europec/EAGE Annual Conference, Madrid, Spain, June 2005.

[60] J. P. Aguilar-López, T. Bogaard, and H. H. Gerke, "Dualpermeability model improvements for representation of preferential flow in fractured clays," Water Resources Research, vol. 56, p. e2020WR027304, 2020.

[61] T. N. Libson and J. R. Henry, "Case histories: identification of and remedial action for liquid loading in gas wells-intermediate shelf gas play," Journal of Petroleum Technology, vol. 32, pp. 685-693, 1980.

[62] H. Hematpur, S. M. Mahmood, N. H. Nasr, and K. A. Elraies, "Foam flow in porous media: concepts, models and challenges," Journal of Natural Gas Science and Engineering, vol. 53, pp. 163-180, 2018.

[63] E. J. Hutlas and W. R. Granberry, "Practical approach to removing gas well liquids," Journal of Petroleum Technology, vol. 24, pp. 916-922, 1972.

[64] F. Ahmad and M. K. Zahoor, "A paradigm shift: higher recovery from water-drive gas reservoirs producing through wells having bigger size completion," in Proceedings of the PAPG/SPE Pakistan Section Annual Technical Conference and Exhibition, Islamabad, Pakistan, November 2016.

[65] W. C. Bugbee, "Artificial lift of water in gas wells," in Proceedings of the North Africa Technical Conference and Exhibition, Cairo, Egypt, February 2012.

[66] C. L. Brady and S. J. Morrow, "Economic assessment of artificial lift in low-pressure, tight gas sands in Ochiltree country, Texas," in Proceedings of the SPE Mid-Continent Gas Symposium, Amarillo, TX, USA, May 1994.

[67] G. N. Ozan, Production System for Optimization for Submersible Pump Lifted Wells: A Case Study, The Middle East Technical University, Ankara, Turkey, 2004.

[68] D. R. Brouwer and J. D. Jansen, "Dynamic optimization of water flooding with smart wells using optimal control theory," in Proceedings of the European Petroleum Conference, Aberdeen, UK, October 2002.

[69] H. Gai, "Downhole flow control optimization in the worlds 1st extended reach multilateral well at wytch farm," in Proceedings of the SPE/IADC Drilling Conference, Amsterdam, Netherlands, February 2001.

[70] A. Ajayi and M. Konopczynski, "A dynamic optimisation technique for simulation of multi-zone intelligent well systems in a reservoir development," in Proceedings of the SPE Offshore Europe Oil and Gas Exhibition and Conference, Aberdeen, UK, September 2003.

[71] L. J. Durlofsky and K. Aziz, "Optimization of smart well control," in Proceedings of the SPE International Thermal Operations and Heavy Oil Symposium and International 
Horizontal Well Technology Conference, Calgary, Canada, November 2002.

[72] M. M. J. J. Naus, N. Dolle, and J. D. Jansen, "Optimization of commingled production using infinitely variable inflow control valves," in Proceedings of the SPE Annual Technical Conference and Exhibition, Houston, TX, USA, September 2004.

[73] M. Armenta and A. K. Wojtanowicz, "Incremental recovery using dual-completed wells in gas reservoirs with bottom water drive: a feasibility study," in Proceedings of the Canadian International Petroleum Conference, Calgary, Canada, June 2003.

[74] M. Armenta and A. K. Wojtanowicz, "Operating dual-completed well to increase gas recovery in low productivity gas reservoirs with water production problems," in Proceedings of the Canadian International Petroleum Conference, Calgary, Canada, June 2004.

[75] J. R. Nichol and J. Marsh, "Downhole gas/water separation: engineering assessment and field experience," in Proceedings of the SPE Annual Technical Conference and Exhibition, San Antonio, TX, USA, October 1997.

[76] M. Boussa, "Production optimization of gas wells: problem of water influx," in Proceedings of the SPE International Thermal Operations and Heavy Oil Symposium and Western Regional Meeting, Bakersfield, CA, USA, March 2004.

[77] J. L. Rike, "Squeeze cementing: state of the art," Journal of Petroleum Technology, vol. 34, pp. 37-45, 1982.

[78] H. Chaabouni, P. Enkababian, K. S. Chan, P. Cheneviere, P. Falxa, and C. Urbanzik, "Successful innovative watershutoff operations in low-permeability gas wells," in Proceedings of the SPE Middle East Oil and Gas Show and Conference, Manama, Bahrain, March 2007.

[79] A. BenAmara, "Gas lift-past \& future," in Proceedings of the SPE Middle East Artificial Lift Conference and Exhibition, Manama, Bahrain, November 2016.

[80] A. H. Shar, "Optimization of gas well productivity by controlling water production," in Proceedings of the SPE/PAPG Annual Technical Conference, Islamabad, Pakistan, November 2005.

[81] A. Zaitoun, N. Kohler, and Y. Guerrini, "Improved polyacrylamide treatments for water control in producing wells," Journal of Petroleum Technology, vol. 43, pp. 862-867, 1991.

[82] D. D. Sparlin and R. W. Hagen, "Controlling water in producing operations,” World Oil, vol. 199, pp. 137-142, 1984.

[83] A. Zaitoun and N. Kohler, "Two-phase flow through porous media: effect of an adsorbed polymer layer," in Proceedings of the SPE Annual Technical Conference and Exhibition, Houston, TX, USA, October 1988.

[84] S.-B. Mohsen, H. Esfandyari, A. Hashemi, A. Reza, and H. Hamed, "Numerical well test analysis of condensate dropout effects in dual-permeability model of naturally fractured gas condensate reservoirs: case studies in the south of Iran," Mathematical Problems in Engineering, vol. 2021, Article ID 9916914, 10 pages, 2021.

[85] W. G. Routson, M. Neale, and J. R. Penton, "A new blocking agent for waterflood channeling authors," in Proceedings of the Fall Meeting of the Society of Petroleum Engineers of AIME, San Antonio, TX, USA, October 1972.

[86] A. Zaitoun and T. Pichery, "A successful polymer treatment for water coning abatement in gas storage reservoir," in Proceedings of the SPE Annual Technical Conference and Exhibition, New Orleans, LA, USA, September 2001. 